\title{
Review Article \\ Delivery of Nucleic Acids and Nanomaterials by Cell-Penetrating Peptides: Opportunities and Challenges
}

\author{
Yue-Wern Huang, ${ }^{1}$ Han-Jung Lee, ${ }^{2}$ Larry M. Tolliver, ${ }^{1}$ and Robert S. Aronstam ${ }^{1}$ \\ ${ }^{1}$ Department of Biological Sciences, Missouri University of Science and Technology, Rolla, MO 65409-1120, USA \\ ${ }^{2}$ Department of Natural Resources and Environmental Studies, National Dong Hwa University, Hualien 97401, Taiwan \\ Correspondence should be addressed to Yue-Wern Huang; huangy@mst.edu
}

Received 24 July 2014; Revised 18 September 2014; Accepted 23 September 2014

Academic Editor: Pradeep Kumar

Copyright (c) 2015 Yue-Wern Huang et al. This is an open access article distributed under the Creative Commons Attribution License, which permits unrestricted use, distribution, and reproduction in any medium, provided the original work is properly cited.

Many viral and nonviral systems have been developed to aid delivery of biologically active molecules into cells. Among these, cellpenetrating peptides (CPPs) have received increasing attention in the past two decades for biomedical applications. In this review, we focus on opportunities and challenges associated with CPP delivery of nucleic acids and nanomaterials. We first describe the nature of versatile CPPs and their interactions with various types of cargoes. We then discuss in vivo and in vitro delivery of nucleic acids and nanomaterials by CPPs. Studies on the mechanisms of cellular entry and limitations in the methods used are detailed.

\section{Introduction}

1.1. Cell-Penetrating Peptides. The plasma membrane plays essential roles in selective permeability, osmotic balance, compartmentalization, and cellular uptake. Small polar molecules such as ions, amino acids, and sugars enter cells through specific carriers and channels in the membrane. Larger macromolecules, such as proteins, DNAs, and RNAs, are generally unable to use this mode of entry. Consequently, delivery tools have been developed to facilitate cellular uptake of large molecules for basic research and biomedical applications (Figure 1). These include mechanical and electrical transfection techniques such as microinjection, bioballistics, hydrodynamic force, ultrasonic nebulization, electroporation, chemical/biochemical methods such as calcium phosphate coprecipitation, membrane fusion catalyzed by artificial lipids, peptides/proteins, dendrimers, adenovirusassociated virus vectors, and lentiviral vectors [1]. Some of these methods are suitable for in vitro or in vivo use, while others are suitable for both. These delivery methods can also be categorized as involving viral or nonviral carrier systems. Due to safety reasons, nonviral delivery methods such as peptide- and lipid-based systems have received more attention over the past 20 years than viral methods.
Advantages of nonviral systems are ease and flexibility of assembly, minimal toxicity, and low levels of immunogenicity and insertional mutagenesis.

Among nonviral delivery methods, cell-penetrating peptides (CPPs) have become increasingly popular. The first CPP was discovered by two independent groups and is comprised of a protein transduction domain (PTD) derived from the transactivator of transcription (Tat) of the human immunodeficiency virus type 1 (HIV-1) $[2,3]$. This domain contains eleven amino acids (YGRKKRRQRRR) that are responsible for cellular entry of Tat [4]. Later, a variety of CPPs are derived from natural, chimeric, and synthetic sources (Table 1) [5, 6]. In general, CPPs are (1) less than 30 amino acids, (2) rich in arginine and lysine, (3) positively charged or amphipathic, (4) easy to prepare, and (5) nontoxic [7].

In general, the efficiency of a CPP in mediating cellular uptake is a function of its total electric charge and amino acid sequence insofar as these properties determine its 3D structures and potential interactions with membranes molecules [8-10]. In particular, secondary amphipathicity is a critical determinant of cellular uptake $[9,11-13]$. Data bases and predictive simulation models are available for identifying biomimetic cell-penetrating peptides based upon an array of protein characteristics [14-16]. 


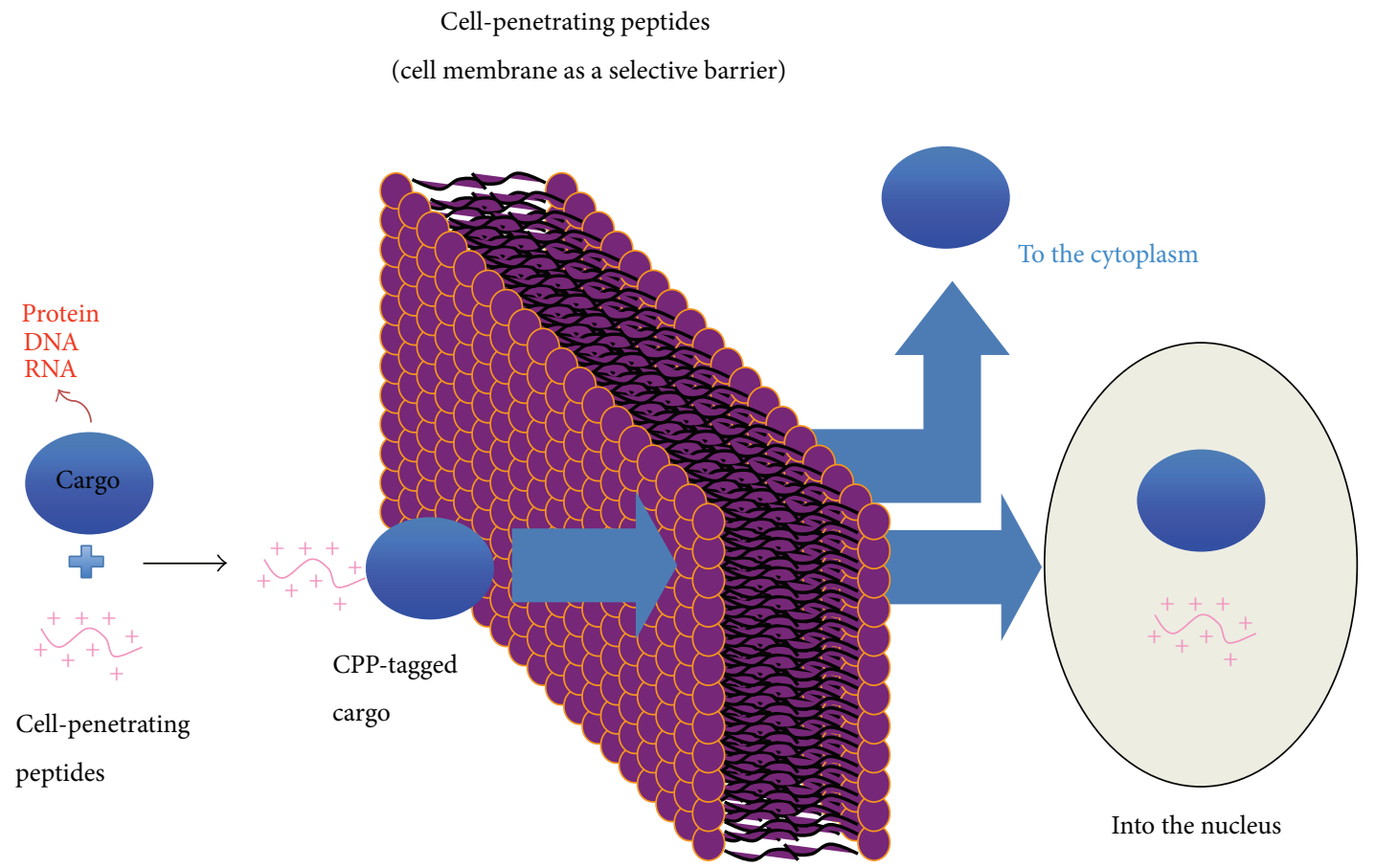

FIGURE 1: Cell-penetrating peptides as a tool to deliver biologically active molecules.

TABLE 1: A variety of cell-penetrating peptides mentioned in this paper.

\begin{tabular}{llc}
\hline CPP & Amino acid sequence & References \\
\hline Viral or natural CPPs & & {$[31-35]$} \\
HIV Tat & YGRKKRRQRRR & {$[35]$} \\
HIV Rev & TRQARRNRRRRWRERQR & {$[35]$} \\
FHV coat & RRRRNRTRRNRRRVR & {$[34]$} \\
HSV-1 protein VP22 & DAATATRGRSAASRPTERPRAPARSASRPRRPVD & {$[31,33,36,37]$} \\
Penetratin & RQIKIWFQNRRMKWKK & {$[31]$} \\
EB1 (penetratin analog) & LIRLWSHLIHIWFQNRRLKWKKK & {$[31,34,38-40]$} \\
MPG & GALFLGFLGAAGSTMGAWSQPKKKRKV & {$[41-44]$} \\
Polyarginines & & {$[31,34,41,42,45]$} \\
PR9 & FFLIPKGRRRRRRRRR & {$[46-48]$} \\
SR9 & RRRRRRRRR & {$[41-44,46]$} \\
IR9 & GLFEAIEGFIENGWEGMIDGWYGRRRRRRRRR & {$[31,36]$} \\
HR9 & CHHHHHRRRRRRRRHHHHHC & {$[31,49]$} \\
Engineered CPPs & & {$[13]$} \\
Transportan & CLIKKALAALAKLNIKLLYGASNLTWG & {$[13]$} \\
CADY & GLWRALWRLLRLWRLLWRA & {$[9]$} \\
C6 & RLLRLLLRLWRRLLRLLR & {$[9]$} \\
C6M1 & RLWRLLWRLWRRLWRLLR & {$[9]$} \\
PF20 (and variants, see [9]) & LLKLLKKLLKLLKKLLKLL & {$[25]$} \\
NAP & KALKLKLALALLAKLKLA & Stearyl-KALKLKLALALLAKLKLA \\
Steryl-NAP & GGG[ARKKAAKA $]_{4}$ & \\
POD & &
\end{tabular}




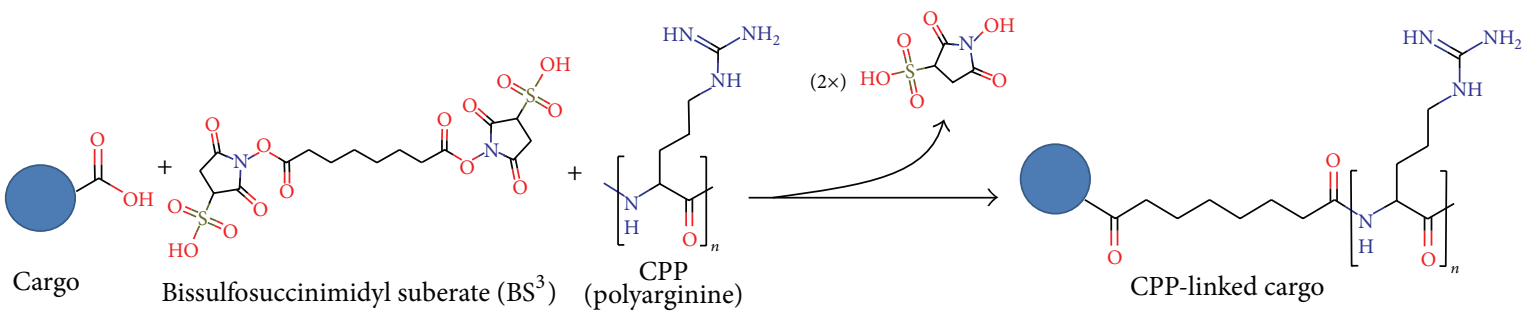

(a)

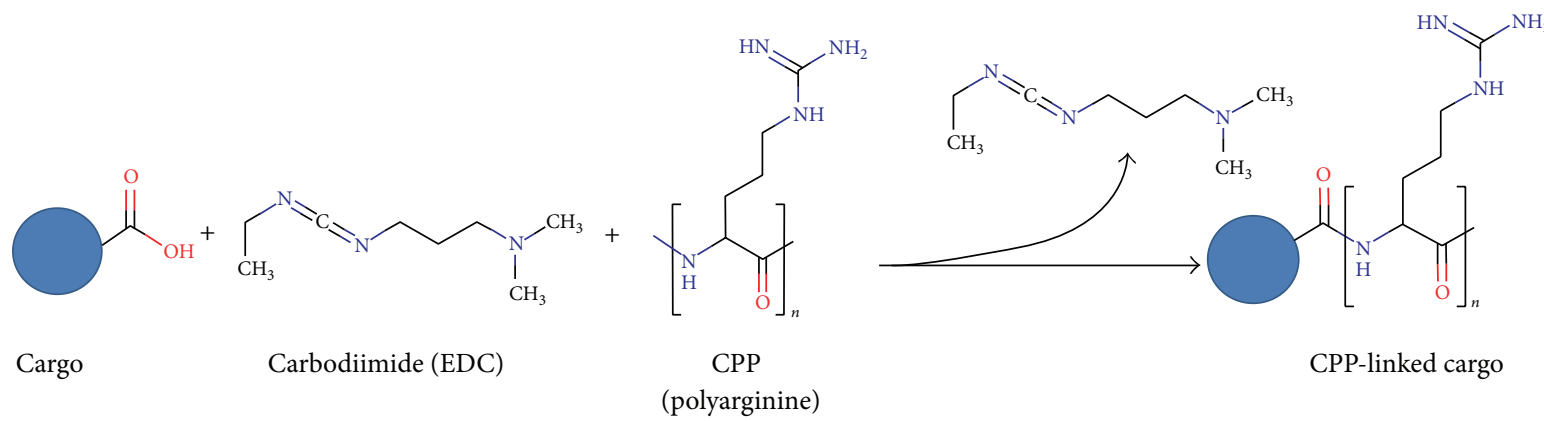

(b)



(c)

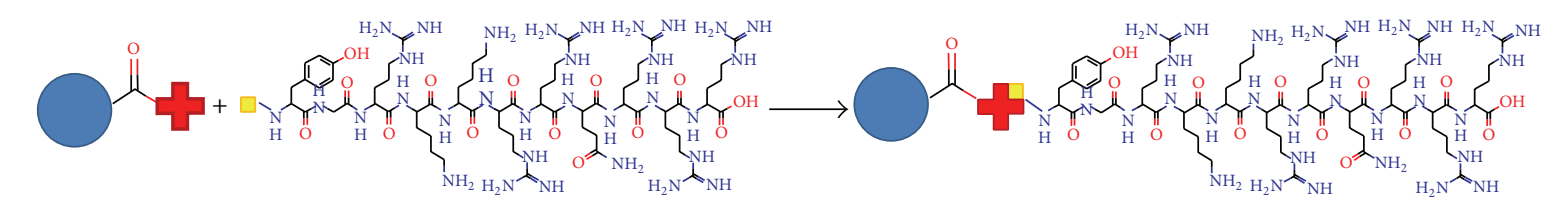

Streptavidin-tagged cargo

Biotinylated CPP (Tat PTD)

CPP-linked cargo

(d)

FIGURE 2: Reaction scheme for linking CPPs to cargoes. The cargoes can be linked to the CPPs through a covalent linkage method such as (a) bissulfosuccinimidyl suberate, (b) carbodiimide, or (c) Sulfo-SMCC with a cysteine-modified CPP, or through a noncovalent method such as (d) biotin-streptavidin interaction.

1.2. Versatile CPPs and Their Interactions with Cargoes. CPPs have been used as carriers of DNA, RNA, protein, nanomaterials, and pharmaceuticals. Association between CPP and cargo can be either covalent or noncovalent. Covalent interactions have been achieved by sulfosuccinimidyl suberate linkage, carbodiimide conjugation, and thiol-amine coupling. Noncovalent interactions include biotin-streptavidin interactions, electrostatic interactions, and metal-affinity interactions [18-20] (Figure 2). Covalent strategies have been used to conjugate antibody fragments, drugs, and fluorescent labels. Covalent linking ensures strong association between
$\mathrm{CPP}$ and cargo and high transduction efficiency. However, the covalent-linking procedure may be labor-intensive, timeconsuming, and costly. The yield of the CPP-cargo covalent complex also decreases during separation from the unbound CPPs and cargoes. Further, to achieve covalent linking, cargoes are chemically modified, which may compromise functionality. Schwarze et al. first demonstrated the delivery of CPP-fusion proteins into various tissues in mice [21]. Subsequently, others showed that CPPs can carry covalently linked nucleic acids and nanomaterials into cells of a variety cell lines [22-24]. Johnson et al. used the cell-penetrating 
peptide POD (peptide for ocular delivery) to deliver PODGFP fusion protein to retina, cornea, and skin [25]. Chang et al. first described a CPP-mediated covalent protein transduction in plants [26].

The advantages of noncovalent binding between CPP and cargo are ease of use, ease of production, versatility with respect to cargo composition, and preservation of cargo functionality [27]. Noncovalent strategies have been used to deliver siRNA, plasmids, and splice correcting oligonucleotides. Noncovalent bonding was applied to the delivery of green fluorescent protein (GFP), collagen and insulin, into mouse skin tissues $[28,29]$. We and others have successfully used the noncovalent delivery in several representative organisms of prokaryotes and unicellular yeasts, including cyanobacteria, bacteria, archaea, algae, fungi, and yeasts. However, noncovalent delivery was not successful in multicellular fungi and green algae [30].

\section{CPPs Delivery of Nucleic Acids}

2.1. siRNA Delivery. RNA interference (RNAi) is an evolutionarily conserved mechanism of gene expression regulation in animals and plants [84]. Endogenous pre-microRNAs (pre-miRNAs) are synthesized and processed in the nucleus and then transported to cytoplasm. The pre-miRNA is shortened and processed in the cytoplasm by an RNAse III enzyme (Dicer) to become mature microRNA. A multienzyme complex that includes argonaute 2 and the RNA-induced silencing complex (RISC) binds to the microRNA and eliminates one strand. This activated complex then binds to an mRNA strand that possesses a complementary sequence, thereby inactivating its expression [85-87]. Utilizing this principle, synthetic RNA molecules (small interfering RNA, siRNA) of 20-25 base pairs in length have been developed to manipulate the expression of specific genes (Figure 3). This technique represents a new treatment modality in cancer, infectious diseases, and genetic disorders. Currently there are more than 20 siRNAs undergoing clinical trials in various stages [88]. The biggest challenge of this technique is delivery of siRNA across the cytoplasmic membrane. Carriers are needed to overcome this barrier and CPPs represent an obvious attractive means for siRNA internalization.

The CPPs transportan, penetratin, amphipathic peptides, and polyarginine have been extensively used to covalently or noncovalently deliver siRNA into animal and plant cells [31-33, 36-40, 45, 49, 89, 90]. Target gene products of siRNAs include Luciferase, SOD1, EGFP, p38 MAP kinase, CDK9, VEGF, p53, and Oct-3/4. Stable noncovalent CPP and siRNA complexes can be formed by CPP/siRNA electrostatic interactions. Alternately, CPPs can be covalently linked to siRNA duplexes through disulfide bond formation in which CPPs containing $\mathrm{N}$-terminal cysteines are conjugated to siRNA molecules with a $5^{\prime}$-thiol modified siRNA sense strand $[31,34]$. It is critical to purify the CPP/siRNA complex in order to investigate transduction efficiency of the covalent CPP-siRNA complexes. Otherwise, it is difficult to discern the contribution of noncovalent CPP-siRNA complexes to the transduction response.
Potential drawbacks of direct conjugation of cationic CPPs with anionic siRNAs are charge neutralization, inactivation of the CPP, and aggregation/precipitation, which may limit siRNA entry into the cells [33, 91, 92]. Eguchi and Dowdy invented an elegant design that fused a Tat PTD with a double-stranded RNA-binding domain (dsRBD) [93]. This design allowed siRNA to bind to dsRBD while leaving PTD to induce cellular uptake in primary and transformed cells. This tactic was applied in a mouse model of glioblastoma to deliver two siRNAs for simultaneous silencing of EGFR and Akt2. The result was selective destruction of tumor cells and improved longevity of cancerous mice [94]. Clearly, CPPmediated siRNA delivery has a promising future in disease treatment.

2.2. DNA Delivery. The delivery of functional exogenous DNA into organisms is important for transgenic research and gene therapy. Most studies have focused on CPP-mediated delivery into mammalian cells, although our research team has demonstrated that CPPs can deliver biologically active molecules into a variety of species, including rotifers [46], cyanobacteria [95], insects [41], plants [96], and paramecium [42]. Internalization of CPP-mediated DNA transduction involves a combination of pathways including classical endocytosis, caveolin- and clathrin-dependent endocytosis, macropinocytosis, and direct membrane penetration $[46,96$, 97]. Various strategies have been developed to enhance transduction efficiency. For instance, stearylation of arginine-rich CPPs drastically increases transduction efficiency of plasmid DNA [35, 98], while hemagglutinin-2 (HA2) analogues or chemicals such as chloroquine and polyethylenimine (PEI) enhance transduction efficiency by catalyzing cargo release from endosomes (see Section 4.3).

There have been attempts to deliver biologically active molecules into the nucleus [99]. Molecules can enter the nucleus from the cytoplasm by either passive diffusion or active transport mechanisms. Small molecules less than $10 \mathrm{~nm}$ in diameter or $50-60 \mathrm{kDa}$ in size can diffuse directly through nuclear pore complexes. Most protein molecules are transported by energy-dependent transport mechanisms initiated by nuclear localization signals (NLS). These signals are recognized by importin family proteins that mediate the transport across the nuclear envelope with the participation of Ran proteins [100]. An N-stearylated NLS was found to improve CPP-mediated transfection activity by overcoming cell membrane and nuclear pore barriers [98]. In contrast, we have found that constructs with NLS tag interact with the HA2 sequence thereby limiting delivery. The detailed reason of this NLS interference remained to be elucidated [78].

In addition to penetrating cytoplasmic membrane and nucleus, we demonstrated that a CPP-piggyBac transposase (CPP-PBase) plasmid system could accomplish both protein transduction and transposition [101]. The system was able to synchronously deliver covalently linked PBase and noncovalently linked cis plasmid into human cells. This one-plasmid "transposoduction" has tremendous potential for safe and efficient cell line transformation, gene therapy, and functional genomics. 




(a)
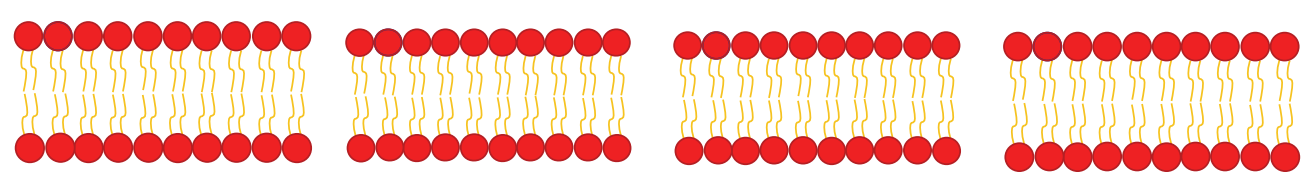

Dicer (dsRBD)

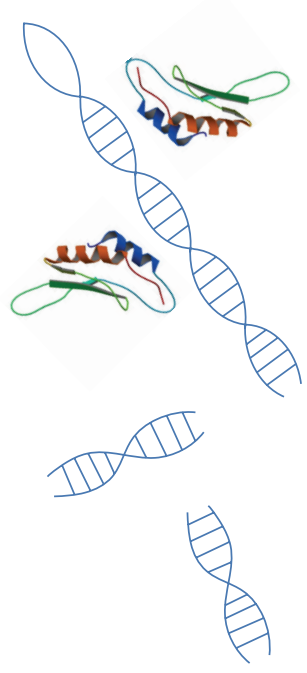

(b)

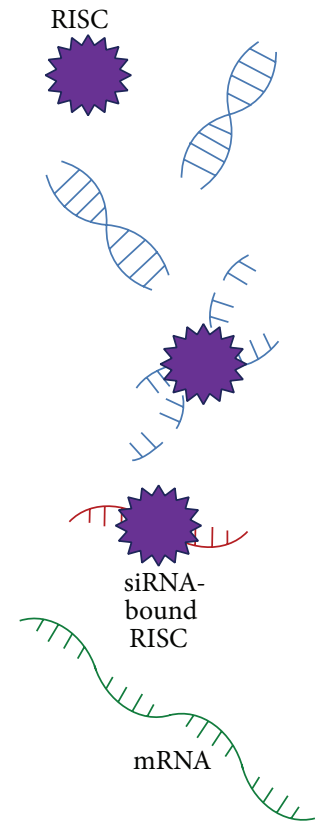

(c)

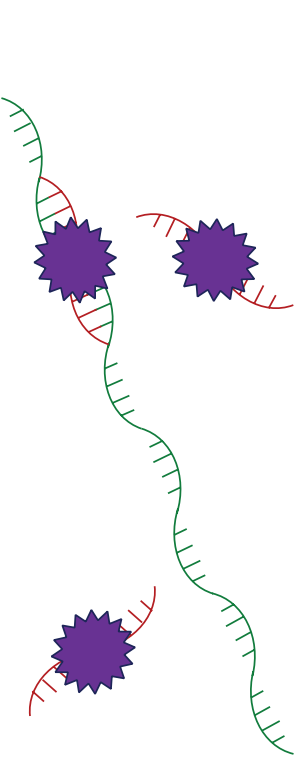

(d)

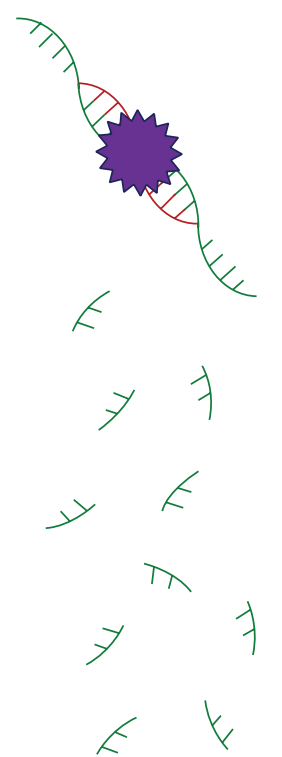

(e)

Figure 3: Simplified conceptual diagram (not drawn proportionally in size) of exogenous siRNA-mediated gene silencing. (a) The siRNA (usually small hairpin RNA, shRNA) can be modified to covalently interact with CPPs and then be transported through the cell membrane. (b) shRNA binds to the double-strand RNA binding domain (dsRBD) of the enzyme Dicer and then is processed. (c) The processed RNA is incorporated into the RNA-induced silencing complex (RISC). The passenger strand RNA is degraded. (d) The guide strand RNA along with the RISC binds to a complementary sequence of a targeted mRNA. (e) The targeted mRNA is degraded and translation disrupted.

\section{CPPs Delivery of Nanomaterials}

The improved sensitivity, resolution, and versatility of fluorescent microscopy and the discovery of fluorescent proteins have revolutionized imaging in basic science and biomedical applications $[102,103]$. These fluorescent proteins have been extensively used for visualizing and tracking molecules in dynamic cellular processes. They may also be useful in disease diagnosis and therapeutic planning. Recently Nguyen et al. advanced the possibility of utilizing fluorescent proteins to improve surgical precision [104]. However, the broad emission spectra of current organic fluorophores impede multiplex imaging, while photobleaching limits their use in long-term imaging $[105,106]$. Furthermore, cell autofluorescence in the visible spectrum and a need of probes that emit in the near-infrared (NIR) region drive the need to develop new imaging probes.

Nanomaterials are materials that have at least one dimension in the range of 1-100 $\mathrm{nm}$. The development of nanomaterials has revolutionized many industries such as computing and semiconductor, optics, energy, and cosmetics [107]. Semiconductor nanocrystals (a.k.a. quantum dots, QDs) possess high optical extinction coefficient, a narrow range of emission wavelength, exceptional resistance to photo- and chemical degradation, and high quantum yield $[108,109]$. These properties make QDs particularly attractive for long-term observation of molecules in live cells and multiplex imaging, as well as tumor targeting and diagnostics in vivo. However, inorganic QDs are not permeable to cytoplasmic membrane and agglomerate easily. Thus, surface modifications of QDs, such as complexing with polyethylene glycol, are required to achieve stable suspension (Figure 4(a)). Even so, QDs are poorly taken up by cells (Figure 4(b)). Josephson et al. first reported increased uptake of iron oxide nanoparticles covalently conjugated with Tat-PTD [110]. These Tat-iron oxide nanoparticle complexes were internalized into lymphocytes and yielded magnetic labeling of cells. This technology opens up the possibility for simultaneous diagnosis and treatment of diseases (i.e., theranostics) when drugs are included in the imaging system.

Stroh et al. successfully labeled primary bone marrow cells with Tat-QD micelles ex vivo and observed the recruitment of the labeled bone marrow-derived precursor cells to the tumor vasculature [111]. This methodology may advance 

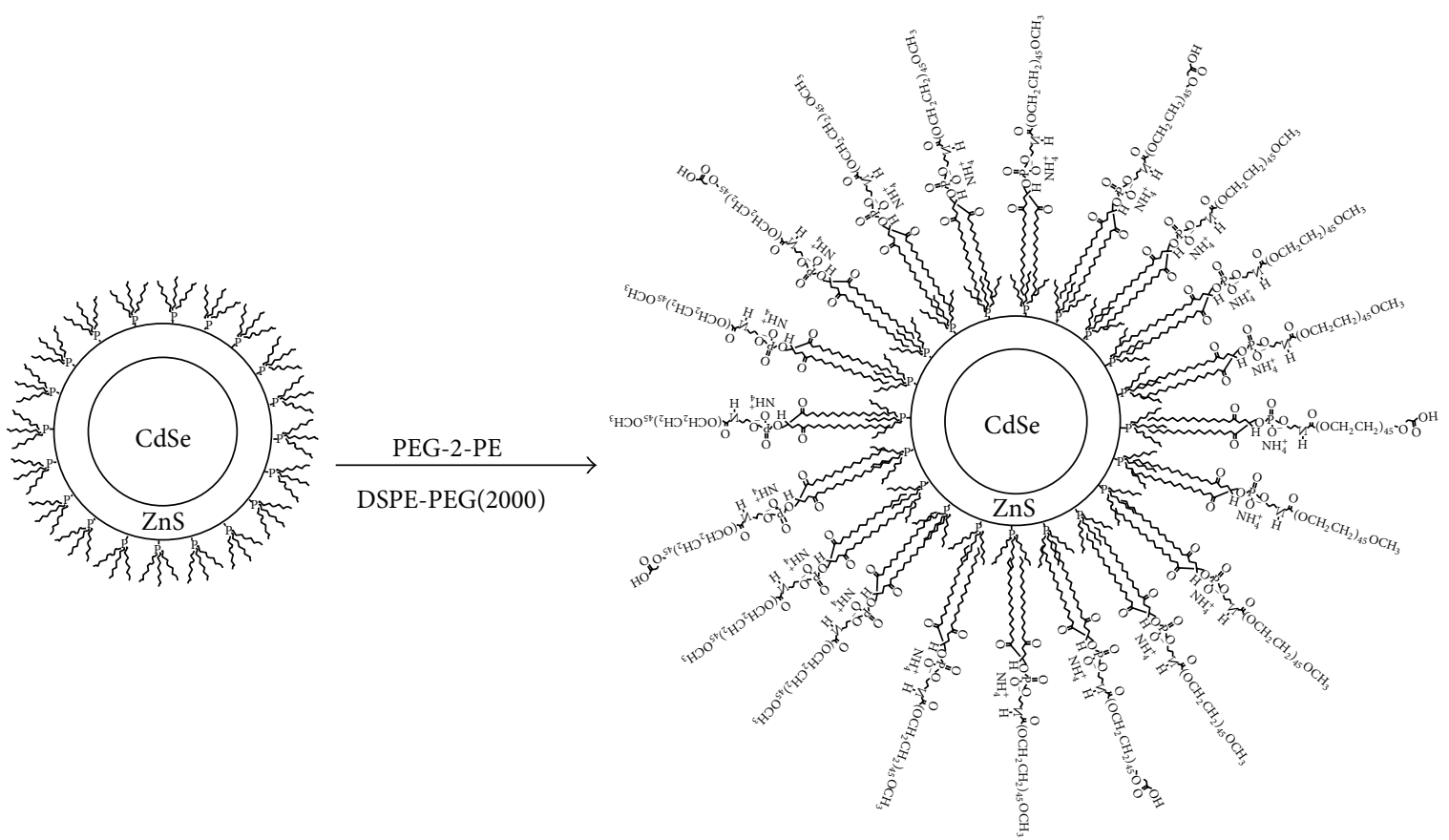

(a)
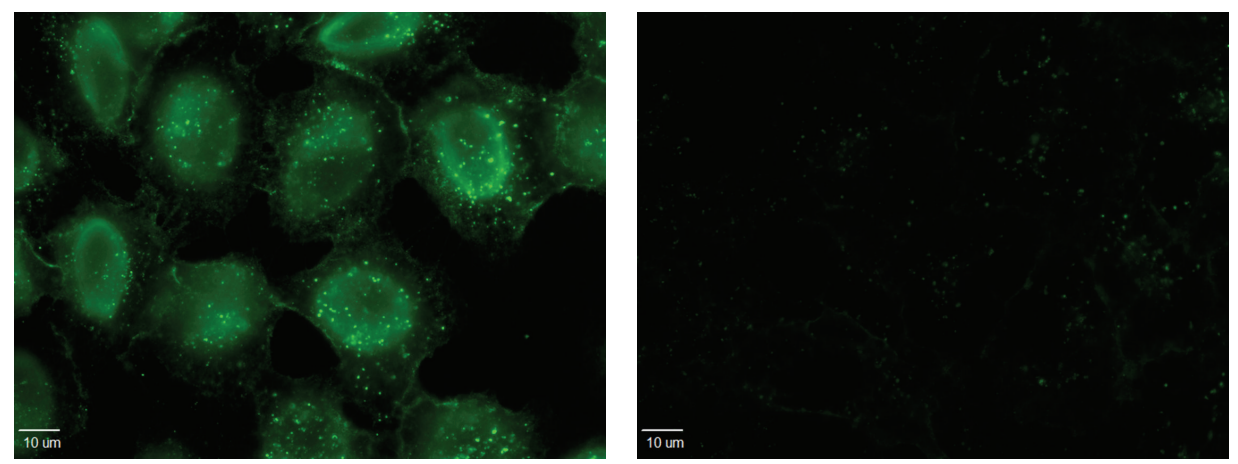

(b)

Figure 4: (a) Synthesis of water-soluble carboxylated CdSe/ZnS quantum dots. Upon addition of ZnS as a shell to protect Cd core, the surface was modified with 1, 2-distearoyl-sn-glycero-3-phosphoethanolamine-N-[carboxy(polyethyleneglycol)-2000] (DSPE-PEG 2000) and 1,2-dipalmitoyl-sn-glycero-3-phosphoethanolamine-N-[methoxy(polyethyleneglycol)-2000] (PEG-2 PE). The amount and ratio of PEG2-PE and DSPE-PEG(200) determine suspension stability in water. (b) Fluorescence of CdSe/ZnS quantum dot in live cells with (left) and without (right) nona-arginine after a 1-hour exposure [17].

our understanding of stem cell proliferation and differentiation. Many other studies have investigated CPP-mediated delivery of QDs into living cells for basic science and biomedical application purposes [17, 24, 43, 44, 46-48, 112-117]. In general, cellular uptake of the CPP/QD complexes includes classical endocytosis, macropinocytosis, and direct membrane penetration. Factors that influence uptake efficiency of $\mathrm{CPP} / \mathrm{QD}$ complexes include the size and the overall surface charge of the complexes. For instance, our data suggest that electropositive charges of CPP/QD complexes (measured as zeta-potential) increase higher transduction efficiency [118].

Although Cd-based QDs at nontoxic levels can be useful in research applications [119], they are not ideal agents for therapeutic purposes. Biocompatible, fluorescent nanodiamonds represent an attractive alternative. Defect center (color center) of nanodiamonds can be created by irradiation with a high power laser beam followed by thermal annealing at $800^{\circ} \mathrm{C}$ [120]. Nanodiamonds thus have been modified producing strong and stable fluorescence with no photoblinking (within $1 \mathrm{~ms}$ ) and no photobleaching [121]. We found that histidine-modified arginine-rich CPP (HR9) can facilitate the cellular uptake of these fluorescent nanodiamonds (Figure 5). Collectively, a combined use of CPPs and nanoscaled materials (with or without fluorescence) may greatly enhance payload and efficiency for imaging and therapeutic uses. 
TABLE 2: Examples of cellular uptake markers and organelle markers for green fluorescent CdSe/ZnS quantum dots in live cell imaging.

\begin{tabular}{|c|c|c|c|c|}
\hline Marker & Function & Color $(\mathrm{Ex} / \mathrm{Em})$ & Incubation time & Conc. \\
\hline FM4-64 & Endocytosis marker & $\operatorname{Red}(506 / 750)$ & $15 \mathrm{~min}$ & $2 \mu \mathrm{M}$ \\
\hline Alexa Fluor 568-Transferrin & Clathrin-dependent endocytosis marker & $\operatorname{Red}(580 / 630)$ & $5 \min$ & $25 \mu \mathrm{g} / \mathrm{mL}$ \\
\hline Alexa Fluor 568-Cholera toxin B & Caveolae-dependent endocytosis marker & $\operatorname{Red}(580 / 630)$ & $10 \mathrm{~min}$ & $5 \mu \mathrm{g} / \mathrm{mL}$ \\
\hline Texas red-Neural Dextran 70 & Macropinocytosis marker & $\operatorname{Red}(595 / 615)$ & $30 \mathrm{~min}$ & $5 \mu \mathrm{M}$ \\
\hline TMR-Dextran & Early endosome marker & Red $(555 / 580)$ & $5 \min$ & $10 \mathrm{mg} / \mathrm{mL}$ \\
\hline Lyso Tracker Red DND 99 & Lysosome marker & Red $(577 / 590)$ & $10 \mathrm{~min}$ & $0.5 \mu \mathrm{M}$ \\
\hline EEA1-Alexa Fluor 568 & Early endosome marker & $\operatorname{Red}(580 / 630)$ & $5 \min$ & $10 \mu \mathrm{g} / \mathrm{mL}$ \\
\hline Lamp-1-Alexa Fluor 568 & Late endosome marker & Red (578/603) & $5 \min$ & $10 \mu \mathrm{g} / \mathrm{mL}$ \\
\hline Mito Tracker Deep 633 & Mitochondria marker & $\operatorname{Red}(640 / 662)$ & $10 \mathrm{~min}$ & $1 \mu \mathrm{M}$ \\
\hline Hoechst 33342 & Nuclei marker & Blue $(352 / 461)$ & $30 \mathrm{~min}$ & $5 \mu \mathrm{M}$ \\
\hline
\end{tabular}

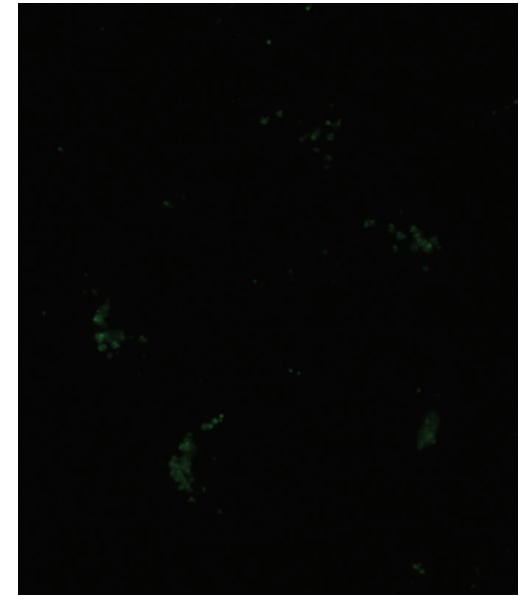

FIGURE 5: HR9 CPP facilitates cellular uptake of green fluorescent nanodiamonds.

\section{Mechanisms of CPP-Mediated Cellular Uptake}

4.1. Complementary Methods to Study Mechanisms of Cellular Uptake. Fixed cell imaging was utilized to study CPPmediated cellular uptake. However, the fixation procedure introduced artifacts and yielded inaccurate data. Live cell imaging has supplanted fixed cell imaging and become a powerful tool to study dynamic cellular process in CPPmediated uptake. Coupled with cellular uptake markers and organelle markers, the subcellular localization of the $\mathrm{CPP} /$ cargo complex can be identified (Table 2). Figure 6 presents a comprehensive workflow of experiments on cellular uptake, intracellular uptake, and subcellular localization. There are some discrepancies among publications regarding the identity of CPP uptake mechanisms due to the limited use of cellular process inhibitors. Although pharmacological inhibitors (Table 3) can be used to inhibit internalization processes, these inhibitors are not completely specific and may suppress more than one cellular uptake pathway. For instance, cytochalasin $\mathrm{D}$ (CytoD) and $\mathrm{N}$-ethylmaleimide
(NEM) inhibit both clathrin- and caveolin-mediated pathways. CytoD also inhibits macropinocytosis. This makes it difficult to evaluate the contributions of different pathways to transduction and complicates the analysis of CPP-mediated uptake mechanisms. To overcome this problem, we suggested that RNAi be used as a complementary method to thoroughly elucidate CPP-mediated uptake mechanism. For instance, in our study with CPP-mediated cellular uptake of CdSe/ZnS quantum dots, pharmacological inhibitors reduced cellular uptake of the noncovalent CPP/QD complex. However, uptake efficiency of the CPP/QD complex was not reduced by siRNAs introduced to knockdown clathrin $\mathrm{HC}$ and caveolin 1 (Figure 7). It is also worth noting that although the effective dose of an inhibitor may be specified by commercial vendors or literature, a pilot study should be conducted to optimize the concentration of an inhibitor for a specific cell line since too high concentration of an inhibitor may be toxic to cells and compromise cellular processes.

4.2. Diverse Cellular Uptake Routes. Understanding the mechanisms underlying CPP-mediated cellular uptake and subcellular localization of the carrier system is needed to improve transduction efficiency and cargo functionality. Our understanding of uptake is still incomplete. Proposed routes of entry include direct membrane penetration and various types of endocytic pathways. Empirical modeling evidence from several studies supports a direct membrane penetration. Initially CPPs bind to the phosphate groups of the phospholipids on the bilayer surface. As the concentrations of CPPs on cell surface increase, the lipid molecules rearrange. Side chains of arginines translocate through the distal layer and form a water pore. Finally, a few CPPs diffuse through the pore, followed by pore closure [122-125].

Most studies of CPP-mediated cellular uptake of nucleic acids and QDs have focused on endocytosis. Endocytosis is an active process whereby cells internalize extracellular material through cytoplasmic membranes. This process is required by certain cells to obtain essential nutrition and excrete cellular waste. At least 10 different types of endocytic pathways involving various molecules have been delineated [126]. Studies of cellular uptake of CPP/cargo complexes have 


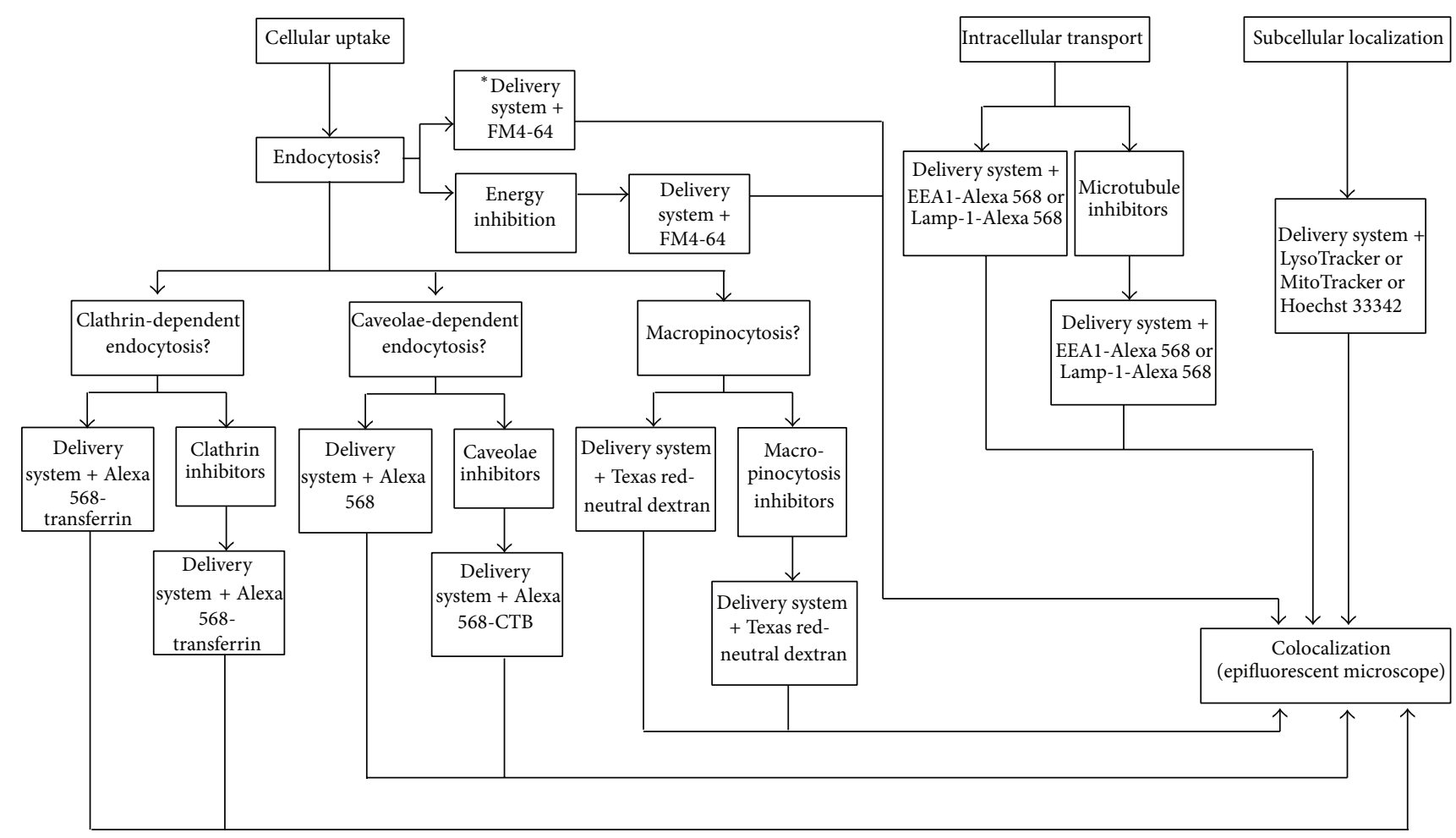

FIGURE 6: Diagram illustrating a comprehensive workflow of experiments designed to characterize the cellular uptake, intracellular uptake, and subcellular localization of CPPs and their cargoes.

focused on three pathways: clathrin-mediated endocytosis, caveolin-dependent endocytosis, and macropinocytosis [17, $34,43,44,97,127,128]$. Future studies should consider other endocytic pathways: CLIC/GEEC, IL2R $\beta$, Arf6-dependent, flotillin-dependent, circular dorsal ruffles, and entosis.

In endocytosis, $\mathrm{CPP} /$ cargo complexes might initially interact with heparan sulfate proteoglycans (a pool of anionic charge on the cell surface). However, Gump et al. recently revised the role of glycosaminoglycans in Tat PTD-mediated induction of macropinocytosis [129]. They found that transduction occurs efficiently in the absence of glycosaminoglycans and sialic acid and that the removal of cell surface proteins totally abolishes transduction. They suggested that additional cell surface protein(s) are necessary for Tat PTD transduction. More studies are needed to identify these proteins are and appreciate their roles in CPP membrane transduction.

Collectively, current data suggest that the routes of the cellular uptake for $\mathrm{CPP} /$ cargo complexes are diverse, reflecting the varied chemical and physical natures of the CPPs and cargoes: entry may simultaneously involve multiple routes.

4.3. Release from Lysosomal Entrapment. A particular problem associated with most of the CPP delivery systems is entrapment in lysosome, which may lead to cargo degradation and, thus, loss of intended functionality. Multiple strategies have been developed to circumvent this problem. One method is to add to the CPP a section of the hemagglutinin
(HA) sequence from the human influenza virus (Table 4). HA is composed of two subunits: hemagglutinin-1 responsible for binding to cells and hemagglutinin-2 (HA2) responsible for lysosomal escape [130]. The N-terminal domain of the HA2 subunit possesses 23 amino acids in a hydrophobic region referred to as fusion peptide [131]. This fusion peptide domain is buried inside the HA trimer in its resting conformation. Upon acidification in the lysosome, an irreversible conformational change of HA2 occurs, exposing the fusion peptide and allowing it to insert into lysosomal membranes. Subsequently a fusion pore is in the membrane is formed, leading to transport of lysosomal contents into the cytosol.

The sequence of CPP-HA2 can be chemically synthesized or the HA2 sequence can be inserted into a CPP-containing plasmid. The advantages of using a peptide synthesizer to produce a CPP-HA2 sequence are high purity, ease of programming the sequence, and flexibility of residue modification as well as molecular conjugation. Disadvantages include limited length of the sequence, loss of yield during purification process, and possible loss of native configuration. The advantages of using a CPP-HA2 plasmid are low cost, time saving for production, and the flexibility to include other desired functional sequences such as imaging molecules. Disadvantages are low purity and considerable time and labor investments. In addition to HA2 and its analogues, the sequences of CPPs can be modified for lysosomal escape. Collectively, these HA2 analogues and sequence variations of CPPs exhibit different degrees of enhanced transduction efficiency, ranging from 0.2 - to 7000 -fold (Table 4). Factors 


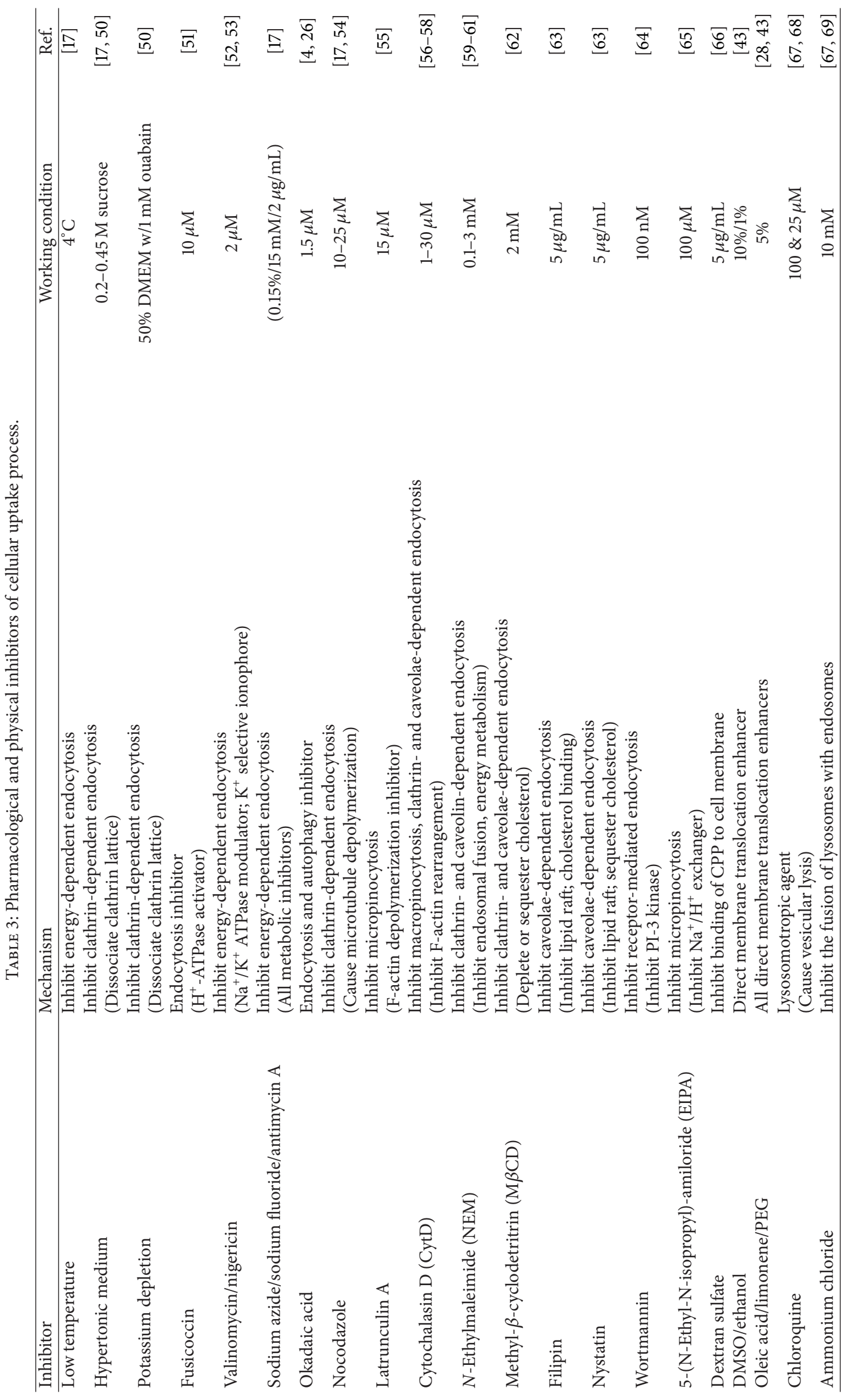




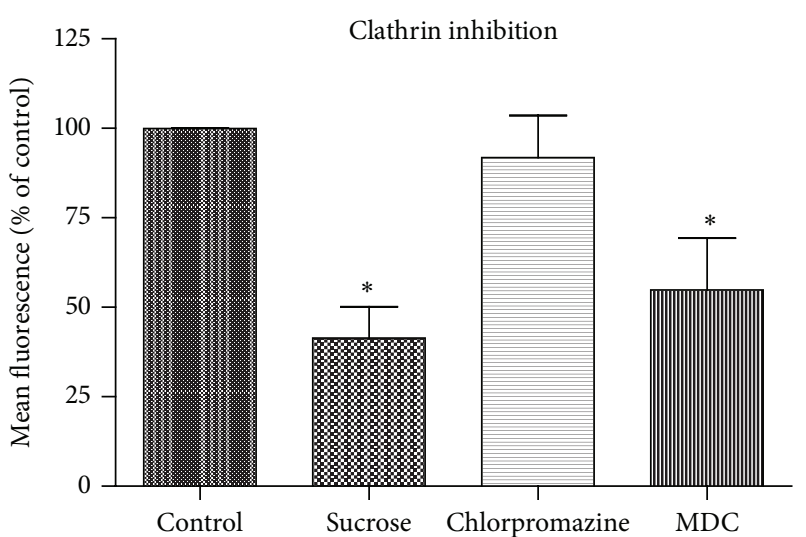

(a)

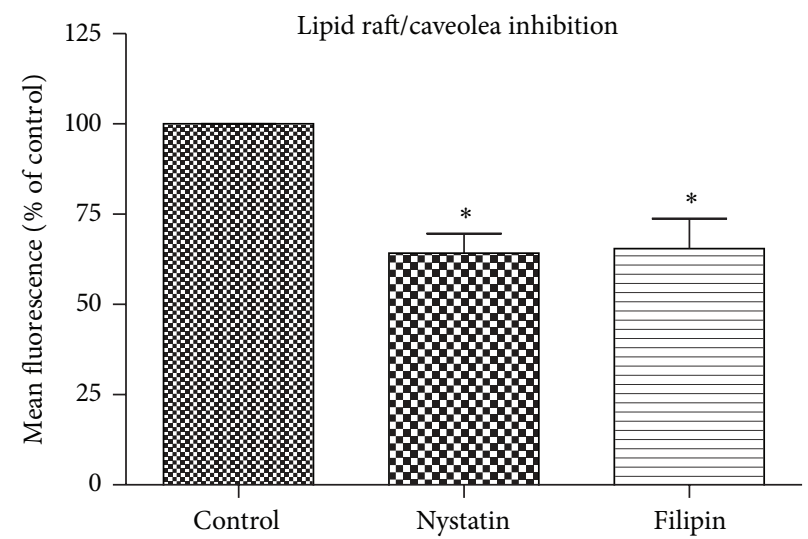

(b)

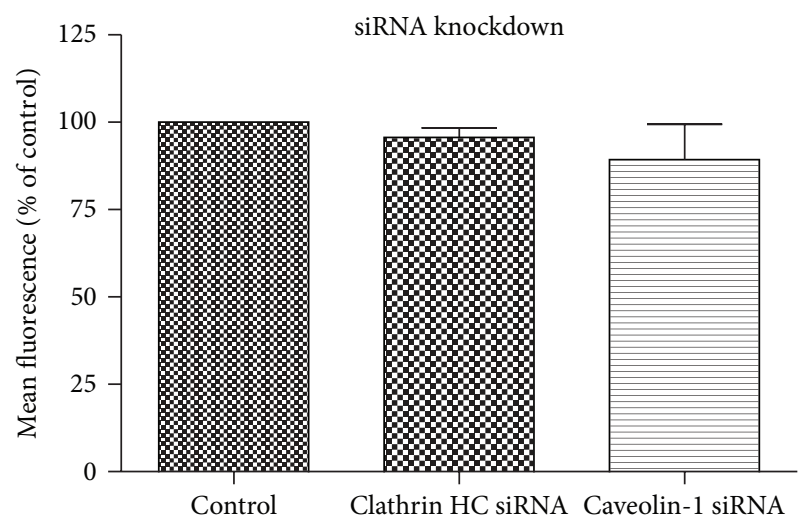

(c)

FIGURE 7: Comparisons of clathrin- and caveolin-dependent cellular uptake pathways using pharmacological inhibitors and RNAi technique [17].

influencing efficiency include the nature of CPPs and HA2, types of cargoes, and sequence orientation of CPP and HA2.

In addition to fusogenic amino acid sequences, chemicals such as chloroquine and polycationic polyethylenimine (PEI) are commonly used to promote lysosomal escape. Chloroquine, a weak base, can enter the cell and accumulate in vesicular compartments following protonation. At low concentrations, chloroquine inhibits endosome acidification and maturation by preventing the accumulation of free protons. As its concentration increases, it starts to accumulate counterions to protons (e.g., chloride ion) in endosomes, leading to endosomal swelling and rupture $[132,133]$. Endosomal release by chloroquine enhances of transduction efficiency [78, 134, 135]. The secondary and tertiary amines of low molecular weight PEI can be protonated in the acidic environment of the endosome, leading to endosomal swelling and rupture. PEI has been used to deliver DNA plasmids with improved transduction efficiency [81,136-139]. The drawback of the PEI polymer is that it is not biodegradable and is highly charged. Thus interaction of this polymer with genetic materials in the cell nucleus might alter gene expression [140-142].

\section{Conclusions}

CPPs are capable of carrying nucleic acids and nanomaterials into cells. CPPs can interact with cargoes in covalent or noncovalent manners. Complementary tools such as pharmacological inhibitors and siRNA are being used to decipher mechanisms of cellular uptake. Depending on the physiochemical natures of the CPP/cargo complex, the mechanism of cellular entry may include classical endocytosis, macropinocytosis, clathrin- and caveolon-dependent pathways, and direct membrane penetration. A variety of chemical and molecular methods have been introduced to overcome lysosomal entrapment in order to achieve higher functional yields. As studies continue to advance our understanding about CPPs, this delivery modality will find considerable usage in clinical setting and basic science research.
Abbreviations
CPP: Cell-penetrating peptide
CDK9: Cyclin-dependent kinase 9
dsRBD: Double-stranded RNA binding domain 


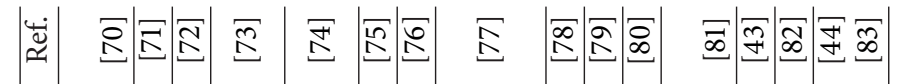

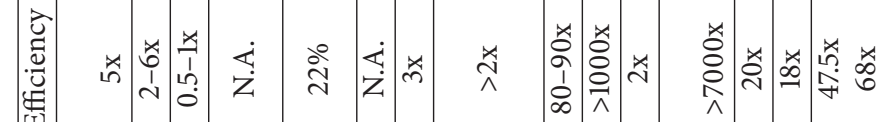



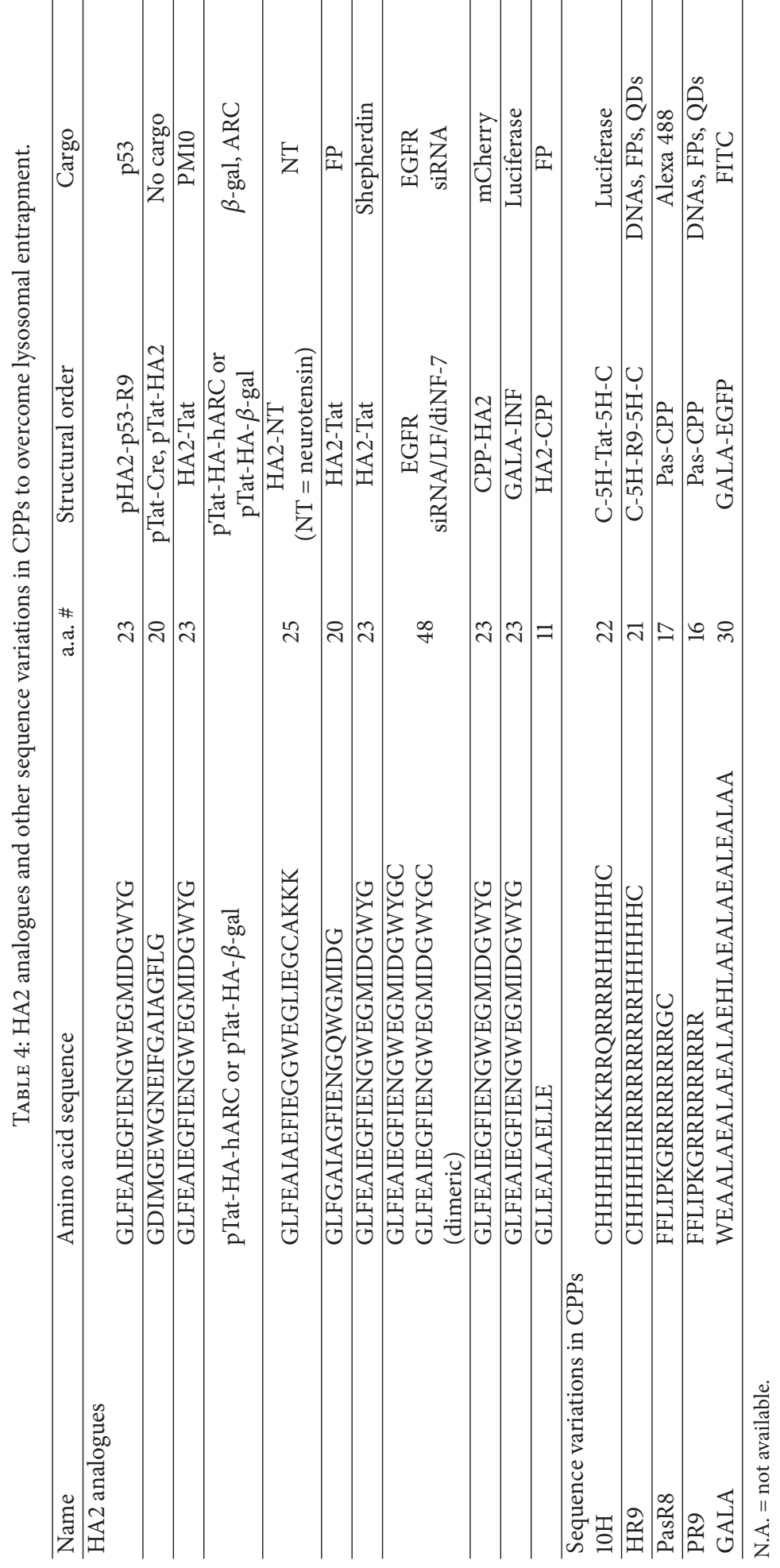


GFP: Green fluorescent protein

EGFP: $\quad$ Enhanced green fluorescent protein

HA: Hemagglutinin

MAP kinase: Mitogen-activated protein kinase

NLS: $\quad$ Nuclear Localization Signal

POD: $\quad$ Peptide for ocular delivery

PTD: $\quad$ Protein transduction domain

PEI: $\quad$ Polyethylenimine

QD: Quantum dot

RISC: $\quad$ RNA-induced silencing complex

RNAi: $\quad$ RNA interference

RNAse: Ribonuclease

siRNA: $\quad$ Small interfering RNA

SOD1: $\quad$ Superoxide dismutase 1

VEGF: Vascular endothelial growth factor.

\section{Conflict of Interests}

The authors confirm no conflict of interests with the contents in this paper.

\section{References}

[1] D. Lou and W. M. Saltzman, "Synthetic DNA delivery systems," Nature Biotechnology, vol. 18, no. 1, pp. 33-37, 2000.

[2] M. Green and P. M. Loewenstein, "Autonomous functional domains of chemically synthesized human immunodeficiency virus tat trans-activator protein," Cell, vol. 55, no. 6, pp. 1179$1188,1988$.

[3] A. D. Frankel and C. O. Pabo, "Cellular uptake of the tat protein from human immunodeficiency virus," Cell, vol. 55, no. 6, pp. 1189-1193, 1988.

[4] E. Vivès, P. Brodin, and B. Lebleu, "A truncated HIV-1 Tat protein basic domain rapidly translocates through the plasma membrane and accumulates in the cell nucleus," The Journal of Biological Chemistry, vol. 272, no. 25, pp. 16010-16017, 1997.

[5] K. M. Wagstaff and D. A. Jans, "Protein transduction: cell penetrating peptides and their therapeutic applications," Current Medicinal Chemistry, vol. 13, no. 12, pp. 1371-1387, 2006.

[6] A. Gräslund, F. Madani, S. Lindberg, Ü. Langel, S. Futaki, and A. Graslund, "Mechanisms of cellular uptake of cell-penetrating peptides," Journal of Biophysics, vol. 2011, Article ID 414729, 10 pages, 2011.

[7] J. Regberg, A. Srimanee, and Ü. Langel, "Applications of cellpenetrating peptides for tumor targeting and future cancer therapies," Pharmaceuticals, vol. 5, no. 9, pp. 991-1007, 2012.

[8] E. D. Karagiannis, A. M. Urbanska, G. Sahay et al., "Rational design of a biomimetic cell penetrating peptide library," ACS Nano, vol. 7, no. 10, pp. 8616-8626, 2013.

[9] J. Regberg, A. Srimanee, M. Erlandsson et al., "Rational design of a series of novel amphipathic cell-penetrating peptides," International Journal of Pharmaceutics, vol. 464, no. 1-2, pp. 111116, 2014.

[10] A. T. Jones and E. J. Sayers, "Cell entry of cell penetrating peptides: tales of tails wagging dogs," Journal of Controlled Release, vol. 161, no. 2, pp. 582-591, 2012.

[11] M. Hällbrink, K. Kilk, A. Elmquist et al., "Prediction of cellpenetrating peptides," International Journal of Peptide Research and Therapeutics, vol. 11, no. 4, pp. 249-259, 2005.
[12] J. Oehlke, A. Scheller, B. Wiesner et al., "Cellular uptake of an $\alpha$ helical amphipathic model peptide with the potential to deliver polar compounds into the cell interior non-endocytically," Biochimica et Biophysica Acta-Biomembranes, vol. 1414, no. 1-2, pp. 127-139, 1998.

[13] M. Jafari, D. N. Karunaratne, C. M. Sweeting, and P. Chen, "Modification of a designed amphipathic cell-penetrating peptide and its effect on solubility, secondary structure, and uptake efficiency," Biochemistry, vol. 52, no. 20, pp. 3428-3435, 2013.

[14] G. E. Tusnády, Z. Dosztányi, and I. Simon, "Transmembrane proteins in the Protein Data Bank: identification and classification," Bioinformatics, vol. 20, no. 17, pp. 2964-2972, 2004.

[15] R. A. Laskowski, E. G. Hutchinson, A. D. Michie, A. C. Wallace, M. L. Jones, and J. M. Thornton, "PDBsum: a Web-based database of summaries and analyses of all PDB structures," Trends in Biochemical Sciences, vol. 22, no. 12, pp. 488-490, 1997.

[16] M. A. Lomize, A. L. Lomize, I. D. Pogozheva, and H. I. Mosberg, "OPM: orientations of proteins in membranes database," Bioinformatics, vol. 22, no. 5, pp. 623-625, 2006.

[17] Y. Xu, B. R. Liu, H.-J. Lee et al., "Nona-arginine facilitates delivery of quantum dots into cells via multiple pathways," Journal of Biomedicine and Biotechnology, vol. 2010, Article ID 948543, 11 pages, 2010.

[18] N. Nitin, L. Laconte, W. J. Rhee, and G. Bao, "Tat peptide is capable of importing large nanoparticles across nuclear membrane in digitonin permeabilized cells," Annals of Biomedical Engineering, vol. 37, no. 10, pp. 2018-2027, 2009.

[19] Y. Wei, N. R. Jana, S. J. Tan, and J. Y. Ying, "Surface coating directed cellular delivery of TAT-functionalized quantum dots," Bioconjugate Chemistry, vol. 20, no. 9, pp. 1752-1758, 2009.

[20] K. Takayama, A. Tadokoro, S. Pujals, I. Nakase, E. Giralt, and S. Futaki, "Novel system to achieve one-pot modification of cargo molecules with oligoarginine vectors for intracellular delivery," Bioconjugate Chemistry, vol. 20, no. 2, pp. 249-257, 2009.

[21] S. R. Schwarze, A. Ho, A. Vocero-Akbani, and S. F. Dowdy, "In vivo protein transduction: delivery of a biologically active protein into the mouse," Science, vol. 285, no. 5433, pp. 1569$1572,1999$.

[22] E. L. Snyder and S. F. Dowdy, "Cell penetrating peptides in drug delivery," Pharmaceutical Research, vol. 21, no. 3, pp. 389-393, 2004.

[23] X. Nan, P. A. Sims, P. Chen, and X. Sunney Xie, "Observation of individual microtubule motor steps in living cells with endocytosed quantum dots," The Journal of Physical Chemistry B, vol. 109, no. 51, pp. 24220-24224, 2005.

[24] B. C. Lagerholm, M. Wang, L. A. Ernst et al., "Multicolor coding of cells with cationic peptide coated quantum dots," Nano Letters, vol. 4, no. 10, pp. 2019-2022, 2004.

[25] L. N. Johnson, S. M. Cashman, S. P. Read, and R. Kumar-Singh, "Cell penetrating peptide POD mediates delivery of recombinant proteins to retina, cornea and skin," Vision Research, vol. 50, no. 7, pp. 686-697, 2010.

[26] M. Chang, J.-C. Chou, C.-P. Chen, B. R. Liu, and H.J. Lee, "Noncovalent protein transduction in plant cells by macropinocytosis," New Phytologist, vol. 174, no. 1, pp. 46-56, 2007.

[27] M. Chang, H. Yue-Wern, R. S. Aronstam, and H.-J. Lee, "Cellular delivery of noncovalently-associated macromolecules by cell-penetrating peptides," Current Pharmaceutical Biotechnology, vol. 15, no. 3, pp. 267-275, 2014. 
[28] Y.-W. Hou, M.-H. Chan, H.-R. Hsu et al., “Transdermal delivery of proteins mediated by non-covalently associated arginine-rich intracellular delivery peptides," Experimental Dermatology, vol. 16, no. 12, pp. 999-1006, 2007.

[29] Y.-H. Wang, C.-P. Chen, M.-H. Chan et al., "Arginine-rich intracellular delivery peptides noncovalently transport protein into living cells," Biochemical and Biophysical Research Communications, vol. 346, no. 3, pp. 758-767, 2006.

[30] B. R. Liu, J.-C. Chou, and H.-J. Lee, "Cell membrane diversity in noncovalent protein transduction," Journal of Membrane Biology, vol. 222, no. 1, pp. 1-15, 2008.

[31] A. Eguchi and S. F. Dowdy, "siRNA delivery using peptide transduction domains," Trends in Pharmacological Sciences, vol. 30, no. 7, pp. 341-345, 2009.

[32] Y.-L. Chiu, A. Ali, C.-Y. Chu, H. Cao, and T. M. Rana, "Visualizing a correlation between siRNA localization, cellular uptake, and RNAi in living cells," Chemistry and Biology, vol. 11, no. 8, pp. 1165-1175, 2004

[33] J. J. Turner, S. Jones, M. M. Fabani, G. Ivanova, A. A. Arzumanov, and M. J. Gait, "RNA targeting with peptide conjugates of oligonucleotides, siRNA and PNA," Blood Cells, Molecules, and Diseases, vol. 38, no. 1, pp. 1-7, 2007.

[34] B. R. Meade and S. F. Dowdy, "Exogenous siRNA delivery using peptide transduction domains/cell penetrating peptides," Advanced Drug Delivery Reviews, vol. 59, no. 2-3, pp. 134-140, 2007.

[35] S. Futaki, W. Ohashi, T. Suzuki et al., "Stearylated argininerich peptides: a new class of transfection systems," Bioconjugate Chemistry, vol. 12, no. 6, pp. 1005-1011, 2001.

[36] A. Muratovska and M. R. Eccles, "Conjugate for efficient delivery of short interfering RNA (siRNA) into mammalian cells," FEBS Letters, vol. 558, no. 1-3, pp. 63-68, 2004.

[37] T. J. Davidson, S. Harel, V. A. Arboleda et al., "Highly efficient small interfering RNA delivery to primary mammalian neurons induces microRNA-like effects before mRNA degradation," Journal of Neuroscience, vol. 24, no. 45, pp. 10040-10046, 2004.

[38] F. Simeoni, M. C. Morris, F. Heitz, and G. Divita, "Insight into the mechanism of the peptide-based gene delivery system MPG: implications for delivery of siRNA into mammalian cells," Nucleic Acids Research, vol. 31, no. 11, pp. 2717-2724, 2003.

[39] P. Lundberg, S. El-Andaloussi, T. Sütlü, H. Johansson, and Ü. Langel, "Delivery of short interfering RNA using endosomolytic cell-penetrating peptides," The FASEB Journal, vol. 21, no. 11, pp. 2664-2671, 2007.

[40] S. Veldhoen, S. D. Laufer, A. Trampe, and T. Restle, "Cellular delivery of small interfering RNA by a non-covalently attached cell-penetrating peptide: quantitative analysis of uptake and biological effect," Nucleic Acids Research, vol. 34, no. 22, pp. 6561-6573, 2006.

[41] Y. J. Chen, B. R. Liu, Y. H. Dai et al., "A gene delivery system for insect cells mediated by arginine-rich cell-penetrating peptides," Gene, vol. 493, no. 2, pp. 201-210, 2012.

[42] Y.-H. Dai, B. R. Liu, H.-J. Chiang, and H.-J. Lee, “Gene transport and expression by arginine-rich cell-penetrating peptides in Paramecium," Gene, vol. 489, no. 2, pp. 89-97, 2011.

[43] B. R. Liu, Y.-W. Huang, J. G. Winiarz, H.-J. Chiang, and H.J. Lee, "Intracellular delivery of quantum dots mediated by a histidine- and arginine-rich HR9 cell-penetrating peptide through the direct membrane translocation mechanism," Biomaterials, vol. 32, no. 13, pp. 3520-3537, 2011.
[44] B. R. Liu, S.-Y. Lo, C.-C. Liu et al., "Endocytic trafficking of nanoparticles delivered by cell-penetrating peptides comprised of nona-arginine and a penetration accelerating sequence," PLoS ONE, vol. 8, no. 6, Article ID e67100, 2013.

[45] Y.-H. Wang, Y.-W. Hou, and H.-J. Lee, "An intracellular delivery method for siRNA by an arginine-rich peptide," Journal of Biochemical and Biophysical Methods, vol. 70, no. 4, pp. 579586, 2007.

[46] B. R. Liu, J.-S. Liou, Y.-J. Chen, Y.-W. Huang, and H.-J. Lee, "Delivery of nucleic acids, proteins, and nanoparticles by arginine-rich cell-penetrating peptides in rotifers ," Marine Biotechnology, vol. 15, no. 5, pp. 584-595, 2013.

[47] B. R. Liu, J.-S. Liou, Y.-W. Huang, R. S. Aronstam, and H.-J. Lee, "Intracellular delivery of nanoparticles and DNAs by IR9 cell-penetrating peptides," PLoS ONE, vol. 8, no. 5, Article ID e64205, 2013.

[48] B. R. Liu, J. G. Winiarz, J. S. Moon et al., "Synthesis, characterization and applications of carboxylated and polyethyleneglycolated bifunctionalized InP/ZnS quantum dots in cellular internalization mediated by cell-penetrating peptides," Colloids and Surfaces B: Biointerfaces, vol. 111, pp. 162-170, 2013.

[49] L. Crombez, G. Aldrian-Herrada, K. Konate et al., "A new potent secondary amphipathic cell-penetrating peptide for siRNA delivery into mammalian cells," Molecular Therapy, vol. 17, no. 1, pp. 95-103, 2009.

[50] X. Wu, X. Zhao, L. Baylor, S. Kaushal, E. Eisenberg, and L. E. Greene, "Clathrin exchange during clathrin-mediated endocytosis," Journal of Cell Biology, vol. 155, no. 2, pp. 291-300, 2001.

[51] F. Johansson, M. Sommarin, and C. Larsson, "Fusicoccin activates the plasma membrane $\mathrm{H}^{+}$-ATPase by a mechanism involving the C-terminal inhibitory domain," Plant Cell, vol. 5, no. 3, pp. 321-327, 1993.

[52] T. G. Hammond, F. O. Goda, G. L. Navar et al., "Membrane potential mediates $\mathrm{H}^{+}$-ATPase dependence of "degradative pathway" endosomal fusion," Journal of Membrane Biology, vol. 162, no. 2, pp. 157-167, 1998.

[53] R. Fuchs, S. Schmid, and I. Mellman, "A possible role for $\mathrm{Na}+, \mathrm{K}+-\mathrm{ATP}$ ase in regulating ATP-dependent endosome acidification," Proceedings of the National Academy of Sciences of the United States of America, vol. 86, no. 2, pp. 539-543, 1989.

[54] T. Suzuki, S. Futaki, M. Niwa, S. Tanaka, K. Ueda, and Y. Sugiura, "Possible existence of common internalization mechanisms among arginine-rich peptides," The Journal of Biological Chemistry, vol. 277, no. 4, pp. 2437-2443, 2002.

[55] D. A. Richards, S. O. Rizzoli, and W. J. Betz, "Effects of wortmannin and latrunculin A on slow endocytosis at the frog neuromuscular junction," Journal of Physiology, vol. 557, no. 1, pp. 77-91, 2004.

[56] M. Stahlhut and B. van Deurs, "Identification of filamin as a novel ligand for caveolin-1: evidence for the organization of caveolin-1-associated membrane domains by the actin cytoskeleton," Molecular Biology of the Cell, vol. 11, no. 1, pp. 325337, 2000.

[57] T. A. Gottlieb, I. E. Ivanov, M. Adesnik, and D. D. Sabatini, "Actin microfilaments play a critical role in endocytosis at the apical but not the basolateral surface of polarized epithelial cells," Journal of Cell Biology, vol. 120, no. 3, pp. 695-710, 1993.

[58] M. R. Jackman, W. Shurety, J. A. Ellis, and J. P. Luzio, "Inhibition of apical but not basolateral endocytosis of ricin and folate in Caco-2 cells by cytochalasin D," Journal of Cell Science, vol. 107, part 9, pp. 2547-2556, 1994. 
[59] J. E. Schnitzer, J. Liu, and P. Oh, "Endothelial caveolae have the molecular transport machinery for vesicle budding, docking, and fusion including VAMP, NSF, SNAP, annexins, and GTPases," The Journal of Biological Chemistry, vol. 270, no. 24, pp. 14399-14404, 1995.

[60] L. Rodriguez, C. J. Stirling, and P. G. Woodman, "Multiple Nethylmaleimide-sensitive components are required for endosomal vesicle fusion," Molecular Biology of the Cell, vol. 5, no. 7, pp. 773-783, 1994.

[61] J. E. Schnitzer, J. Allard, and P. Oh, "NEM inhibits transcytosis, endocytosis, and capillary permeability: implication of caveolae fusion in endothelia," American Journal of Physiology-Heart and Circulatory Physiology, vol. 268, no. 1, part 2, pp. H48-H55, 1995.

[62] A. Subtil, I. Gaidarov, K. Kobylarz, M. A. Lampson, J. H. Keen, and T. E. Mcgraw, "Acute cholesterol depletion inhibits clathrincoated pit budding," Proceedings of the National Academy of Sciences of the United States of America, vol. 96, no. 12, pp. 67756780, 1999.

[63] J. E. Schnitzer, P. Oh, E. Pinney, and J. Allard, "Filipinsensitive caveolae-mediated transport in endothelium: reduced transcytosis, scavenger endocytosis, and capillary permeability of select macromolecules," Journal of Cell Biology, vol. 127, no. 5, pp. 1217-1232, 1994.

[64] N. Araki, M. T. Johnson, and J. A. Swanson, "A role for phosphoinositide 3-kinase in the completion of macropinocytosis and phagocytosis by macrophages," Journal of Cell Biology, vol. 135, no. 5, pp. 1249-1260, 1996.

[65] B. R. Liu, J. F. Li, S. W. Lu et al., "Cellular internalization of quantum dots noncovalently conjugated with arginine-rich cell-penetrating peptides," Journal of Nanoscience and Nanotechnology, vol. 10, no. 10, pp. 6534-6543, 2010.

[66] M. M. Fretz, G. A. Koning, E. Mastrobattista, W. Jiskoot, and G. Storm, "OVCAR-3 cells internalize TAT-peptide modified liposomes by endocytosis," Biochimica et Biophysica ActaBiomembranes, vol. 1665, no. 1-2, pp. 48-56, 2004.

[67] A. Gonzalez-Noriega, J. H. Grubb, V. Talkad, and W. S. Sly, "Chloroquine inhibits lysosomal enzyme pinocytosis and enhances lysosomal enzyme secretion by impairing receptor recycling," Journal of Cell Biology, vol. 85, no. 3, pp. 839-852, 1980.

[68] M. A. Wolfert and L. W. Seymour, "Chloroquine and amphipathic peptide helices show synergistic transfection in vitro," Gene Therapy, vol. 5, no. 3, pp. 409-414, 1998.

[69] P. D’Arcy Hart and M. R. Young, "Ammonium chloride, an inhibitor of phagosome-lysosome fusion in macrophages, concurrently induces phagosome-endosome fusion, and opens a novel pathway: studies of a pathogenic mycobacterium and a nonpathogenic yeast," Journal of Experimental Medicine, vol. 174, no. 4, pp. 881-889, 1991.

[70] H. Michiue, K. Tomizawa, F.-Y. Wei et al., "The $\mathrm{NH}_{2}$ terminus of influenza virus hemagglutinin-2 subunit peptides enhances the antitumor potency of polyarginine-mediated p53 protein transduction," The Journal of Biological Chemistry, vol. 280, no. 9, pp. 8285-8289, 2005.

[71] J. S. Wadia, R. V. Stan, and S. F. Dowdy, “Transducible TAT-HA fusogenic peptide enhances escape of TAT-fusion proteins after lipid raft macropinocytosis," Nature Medicine, vol. 10, no. 3, pp. 310-315, 2004.

[72] T. Yoshikawa, T. Sugita, Y. Mukai et al., "Organelle-targeted delivery of biological macromolecules using the protein transduction domain: potential applications for Peptide aptamer delivery into the nucleus," Journal of Molecular Biology, vol. 380, no. 5, pp. 777-782, 2008.

[73] Å. B. Gustafsson, M. R. Sayen, S. D. Williams, M. T. Crow, and R. A. Gottlieb, "TAT protein transduction into isolated perfused hearts: TAT-apoptosis repressor with caspase recruitment domain is cardioprotective," Circulation, vol.106, no. 6, pp. 735739, 2002.

[74] I. Navarro-Quiroga, J. González-Barrios, F. Barron-Moreno, V. González-Bernal, D. B. Martinez-Arguelles, and D. MartinezFong, "Improved neurotensin-vector-mediated gene transfer by the coupling of hemagglutinin HA2 fusogenic peptide and Vp1 SV40 nuclear localization signal," Molecular Brain Research, vol. 105, no. 1-2, pp. 86-97, 2002.

[75] S. H. Chin Lee, R. Jefferies, P. Watt et al., "In vitro analysis of the TAT protein transduction domain as a drug delivery vehicle in protozoan parasites," Experimental Parasitology, vol. 118, no. 3, pp. 303-307, 2008.

[76] T. Sugita, T. Yoshikawa, Y. Mukai et al., "Improved cytosolic translocation and tumor-killing activity of Tat-shepherdin conjugates mediated by co-treatment with Tat-fused endosomedisruptive HA2 peptide," Biochemical and Biophysical Research Communications, vol. 363, no. 4, pp. 1027-1032, 2007.

[77] S. Oliveira, I. van Rooy, O. Kranenburg, G. Storm, and R. M. Schiffelers, "Fusogenic peptides enhance endosomal escape improving siRNA-induced silencing of oncogenes," International Journal of Pharmaceutics, vol. 331, no. 2, pp. 211-214, 2007.

[78] J. S. Liou, B. R. Liu, A. L. Martin, Y. W. Huang, H. J. Chiang, and H. J. Lee, "Protein transduction in human cells is enhanced by cell-penetrating peptides fused with an endosomolytic HA2 sequence," Peptides, vol. 37, no. 2, pp. 273-284, 2012.

[79] C. Plank, B. Oberhauser, K. Mechtler, C. Koch, and E. Wagner, "The influence of endosome-disruptive peptides on gene transfer using synthetic virus-like gene transfer systems," The Journal of Biological Chemistry, vol. 269, no. 17, pp. 12918-12924, 1994.

[80] I. Neundorf, R. Rennert, J. Hoyer et al., "Fusion of a short HA2-derived peptide sequence to cell-penetrating peptides improves cytosolic uptake, but enhances cytotoxic activity," Pharmaceuticals, vol. 2, no. 2, pp. 49-65, 2009.

[81] S. L. Lo and S. Wang, "An endosomolytic Tat peptide produced by incorporation of histidine and cysteine residues as a nonviral vector for DNA transfection," Biomaterials, vol. 29, no. 15, pp. 2408-2414, 2008.

[82] K. Takayama, I. Nakase, H. Michiue et al., "Enhanced intracellular delivery using arginine-rich peptides by the addition of penetration accelerating sequences (Pas)," Journal of Controlled Release, vol. 138, no. 2, pp. 128-133, 2009.

[83] S. Kobayashi, I. Nakase, N. Kawabata et al., "Cytosolic targeting of macromolecules using a $\mathrm{pH}$-dependent fusogenic peptide in combination with cationic liposomes," Bioconjugate Chemistry, vol. 20, no. 5, pp. 953-959, 2009.

[84] A. Fire, S. Xu, M. K. Montgomery, S. A. Kostas, S. E. Driver, and C. C. Mello, "Potent and specific genetic interference by doublestranded RNA in Caenorhabditis elegans," Nature, vol. 391, no. 6669, pp. 806-811, 1998.

[85] L. Peters and G. Meister, "Argonaute proteins: mediators of RNA silencing," Molecular Cell, vol. 26, no. 5, pp. 611-623, 2007.

[86] C. Wostenberg, J. W. Lary, D. Sahu et al., "The role of human Dicer-dsRBD in processing small regulatory RNAs," PLoS ONE, vol. 7, no. 12, Article ID e51829, 2012.

[87] A. de Fougerolles, H.-P. Vornlocher, J. Maraganore, and J. Lieberman, "Interfering with disease: a progress report on 
siRNA-based therapeutics," Nature Reviews Drug Discovery, vol. 6, no. 6, pp. 443-453, 2007.

[88] R. Kanasty, J. R. Dorkin, A. Vegas, and D. Anderson, "Delivery materials for siRNA therapeutics," Nature Materials, vol. 12, no. 11, pp. 967-977, 2013.

[89] N. Unnamalai, B. G. Kang, and W. S. Lee, "Cationic oligopeptide-mediated delivery of dsRNA for post-transcriptional gene silencing in plant cells," FEBS Letters, vol. 566, no. 1-3, pp. 307310, 2004 .

[90] D. Zeineddine, E. Papadimou, K. Chebli et al., "Oct-3/4 dose dependently regulates specification of embryonic stem cells toward a cardiac lineage and early heart development," Developmental Cell, vol. 11, no. 4, pp. 535-546, 2006.

[91] B. R. Meade and S. F. Dowdy, "Enhancing the cellular uptake of siRNA duplexes following noncovalent packaging with protein transduction domain peptides," Advanced Drug Delivery Reviews, vol. 60, no. 4-5, pp. 530-536, 2008.

[92] A. Eguchi, B. R. Meade, Y.-C. Chang et al., "Efficient siRNA delivery into primary cells by a peptide transduction domaindsRNA binding domain fusion protein," Nature Biotechnology, vol. 27, no. 6, pp. 567-571, 2009.

[93] A. Eguchi and S. F. Dowdy, "Efficient siRNA delivery by novel PTD-DRBD fusion proteins," Cell Cycle, vol. 9, no. 3, pp. 424425, 2010.

[94] H. Michiue, A. Eguchi, M. Scadeng, and S. F. Dowdy, "Induction of in vivo synthetic lethal RNAi responses to treat glioblastoma," Cancer Biology \& Therapy, vol. 8, no. 23, pp. 2306-2313, 2009.

[95] B. R. Liu, Y.-W. Huang, and H.-J. Lee, "Mechanistic studies of intracellular delivery of proteins by cell-penetrating peptides in cyanobacteria," BMC Microbiology, vol. 13, no. 1, article 57, 2013.

[96] S.-W. Lu, J.-W. Hu, B. R. Liu et al., "Arginine-rich intracellular delivery peptides synchronously deliver covalently and noncovalently linked proteins into plant cells," Journal of Agricultural and Food Chemistry, vol. 58, no. 4, pp. 2288-2294, 2010.

[97] J. M. Gump and S. F. Dowdy, "TAT transduction: the molecular mechanism and therapeutic prospects," Trends in Molecular Medicine, vol. 13, no. 10, pp. 443-448, 2007.

[98] H.-Y. Wang, J.-X. Chen, Y.-X. Sun et al., "Construction of cell penetrating peptide vectors with $\mathrm{N}$-terminal stearylated nuclear localization signal for targeted delivery of DNA into the cell nuclei," Journal of Controlled Release, vol. 155, no. 1, pp. 26-33, 2011.

[99] K. H. Bremner, L. W. Seymour, A. Logan, and M. L. Read, "Factors influencing the ability of nuclear localization sequence peptides to enhance nonviral gene delivery ," Bioconjugate Chemistry, vol. 15, no. 1, pp. 152-161, 2004.

[100] Q. Ding, L. Zhao, H. Guo, and A. C. Zheng, "The nucleocytoplasmic transport of viral proteins," Virologica Sinica, vol. 25, no. 2, pp. 79-85, 2010.

[101] C.-Y. Lee, J.-F. Li, J.-S. Liou, Y.-C. Charng, Y.-W. Huang, and H.-J. Lee, "A gene delivery system for human cells mediated by both a cell-penetrating peptide and a piggyBac transposase," Biomaterials, vol. 32, no. 26, pp. 6264-6276, 2011.

[102] O. Shimomura, F. H. Johnson, and Y. Saiga, "Extraction, purification and properties of aequorin, a bioluminescent protein from the luminous hydromedusan, Aequorea," Journal of cellular and comparative physiology, vol. 59, pp. 223-239, 1962.

[103] R. Y. Tsien, “The green fluorescent protein," Annual Review of Biochemistry, vol. 67, pp. 509-544, 1998.

[104] Q. T. Nguyen, E. S. Olson, T. A. Aguilera et al., "Surgery with molecular fluorescence imaging using activatable cellpenetrating peptides decreases residual cancer and improves survival," Proceedings of the National Academy of Sciences of the United States of America, vol. 107, no. 9, pp. 4317-4322, 2010.

[105] A. P. Alivisatos, W. Gu, and C. Larabell, "Quantum dots as cellular probes," Annual Review of Biomedical Engineering, vol. 7, pp. 55-76, 2005.

[106] X. Michalet, F. F. Pinaud, L. A. Bentolila et al., "Quantum dots for live cells, in vivo imaging, and diagnostics," Science, vol. 307, no. 5709, pp. 538-544, 2005.

[107] EPA Office of Research and Development, Nanomaterial Research Strategy, EPA Office of Research and Development, Washington, DC, USA, 2009.

[108] F. Chen and D. Gerion, "Fluorescent CdSe/ZnS nanocrystalpeptide conjugates for long-term, nontoxic imaging and nuclear targeting in living cells," Nano Letters, vol. 4, no. 10, pp. 18271832, 2004.

[109] M. A. Reed, J. N. Randall, R. J. Aggarwal, R. J. Matyi, T. M. Moore, and A. E. Wetsel, "Observation of discrete electronic states in a zero-dimensional semiconductor nanostructure," Physical Review Letters, vol. 60, no. 6, pp. 535-537, 1988.

[110] L. Josephson, C.-H. Tung, A. Moore, and R. Weissleder, "High-efficiency intracellular magnetic labeling with novel superparamagnetic-tat peptide conjugates," Bioconjugate Chemistry, vol. 10, no. 2, pp. 186-191, 1999.

[111] M. Stroh, J. P. Zimmer, D. G. Duda et al., "Quantum dots spectrally distinguish multiple species within the tumor milieu in vivo," Nature Medicine, vol. 11, no. 6, pp. 678-682, 2005.

[112] Y.-W. Huang, H.-J. Lee, B. R. Liu, H.-J. Chiang, and C.-H. $\mathrm{Wu}$, "Cellular internalization of quantum dots," Methods in Molecular Biology, vol. 991, pp. 249-259, 2013.

[113] B. R. Liu, Y.-W. Huang, H.-J. Chiang, and H.-J. Lee, "Cellpenetrating peptide-functionalized quantum dots for intracellular delivery," Journal of Nanoscience and Nanotechnology, vol. 10, no. 12, pp. 7897-7905, 2010.

[114] B. R. Liu, H. J. Chiang, Y. W. Huang, M. H. Chan, H. H. Chen, and H. J. Lee, "Cellular internalization of quantum dots mediated by cell-penetrating peptides," Pharmaceutical Nanotechnology, vol. 1, no. 2, pp. 151-161, 2013.

[115] E. B. Voura, J. K. Jaiswal, H. Mattoussi, and S. M. Simon, “Tracking metastatic tumor cell extravasation with quantum dot nanocrystals and fluorescence emission-scanning microscopy," Nature Medicine, vol. 10, no. 9, pp. 993-998, 2004.

[116] J. B. Delehanty, I. L. Medintz, T. Pons, F. M. Brunel, P. E. Dawson, and H. Mattoussi, "Self-assembled quantum dot-peptide bioconjugates for selective intracellular delivery," Bioconjugate Chemistry, vol. 17, no. 4, pp. 920-927, 2006.

[117] G. Ruan, A. Agrawal, A. I. Marcus, and S. Nie, "Imaging and tracking of tat peptide-conjugated quantum dots in living cells: new insights into nanoparticle uptake, intracellular transport, and vesicle shedding," Journal of the American Chemical Society, vol. 129, no. 47, pp. 14759-14766, 2007.

[118] B. R. Liu, M.-H. Chan, H.-H. Chen, S.-Y. Lo, Y.-W. Huang, and H.-J. Lee, "Effects of surface charge and particle size of cell-penetrating peptide/nanoparticle complexes on cellular internalization," in Cell Membrane, I. Mandraccia and G. Slavin, Eds., pp. 43-57, Nova Science, 2013.

[119] G. Von Maltzahn, D.-H. Min, Y. Zhang et al., "Nanoparticle self-assembly directed by antagonistic kinase and phosphatase activities," Advanced Materials, vol. 19, no. 21, pp. 3579-3583, 2007. 
[120] T.-L. Wee, Y.-W. Mau, C.-Y. Fang, H.-L. Hsu, C.-C. Han, and H.-C. Chang, "Preparation and characterization of green fluorescent nanodiamonds for biological applications," Diamond and Related Materials, vol. 18, no. 2-3, pp. 567-573, 2009.

[121] Y.-R. Chang, H.-Y. Lee, K. Chen et al., "Mass production and dynamic imaging of fluorescent nanodiamonds," Nature Nanotechnology, vol. 3, no. 5, pp. 284-288, 2008.

[122] M. Reuter, C. Schwieger, A. Meister, G. Karlsson, and A. Blume, "Poly-1-lysines and poly-l-arginines induce leakage of negatively charged phospholipid vesicles and translocate through the lipid bilayer upon electrostatic binding to the membrane," Biophysical Chemistry, vol. 144, no. 1-2, pp. 27-37, 2009.

[123] N. Schmidt, A. Mishra, G. H. Lai, and G. C. L. Wong, "Argininerich cell-penetrating peptides," FEBS Letters, vol. 584, no. 9, pp. 1806-1813, 2010.

[124] G. Ter-Avetisyan, G. Tünnemann, D. Nowak et al., "Cell entry of arginine-rich peptides is independent of endocytosis," The Journal of Biological Chemistry, vol. 284, no. 6, pp. 3370-3378, 2009.

[125] H. D. Herce, A. E. Garcia, J. Litt et al., "Arginine-rich peptides destabilize the plasma membrane, consistent with a pore formation translocation mechanism of cell-penetrating peptides," Biophysical Journal, vol. 97, no. 7, pp. 1917-1925, 2009.

[126] G. J. Doherty and H. T. McMahon, "Mechanisms of endocytosis," Annual Review of Biochemistry, vol. 78, pp. 857-902, 2009.

[127] A. van den Berg and S. F. Dowdy, "Protein transduction domain delivery of therapeutic macromolecules," Current Opinion in Biotechnology, vol. 22, no. 6, pp. 888-893, 2011.

[128] M. C. Shin, J. Zhang, K. A. Min et al., "Cell-penetrating peptides: achievements and challenges in application for cancer treatment," Journal of Biomedical Materials Research Part A, vol. 102, no. 2, pp. 575-587, 2014.

[129] J. M. Gump, R. K. June, and S. F. Dowdy, "Revised role of glycosaminoglycans in TAT protein transduction domainmediated cellular transduction," The Journal of Biological Chemistry, vol. 285, no. 2, pp. 1500-1507, 2010.

[130] J. J. Skehel and M. D. Waterfield, "Studies on the primary structure of the influenza virus hemagglutinin," Proceedings of the National Academy of Sciences of the United States of America, vol. 72, no. 1, pp. 93-97, 1975.

[131] S. A. Wharton, S. R. Martin, R. W. H. Ruigrok, J. J. Skehel, and D. C. Wiley, "Membrane fusion by peptide analogues of influenza virus haemagglutinin," Journal of General Virology, vol. 69, no. 8, pp. 1847-1857, 1988.

[132] P. Erbacher, A. C. Roche, M. Monsigny, and P. Midoux, "Putative role of chloroquine in gene transfer into a human hepatoma cell line by DNA/lactosylated polylysine complexes," Experimental Cell Research, vol. 225, no. 1, pp. 186-194, 1996.

[133] I. Mellman, R. Fuchs, and A. Helenius, "Acidification of the endocytic and exocytic pathways," Annual Review of Biochemistry, vol. 55, pp. 663-700, 1986.

[134] I. Nakase, S. Kobayashi, and S. Futaki, "Endosome-disruptive peptides for improving cytosolic delivery of bioactive macromolecules," Biopolymers, vol. 94, no. 6, pp. 763-770, 2010.

[135] S. Yang, D. J. Coles, A. Esposito, D. J. Mitchell, I. Toth, and R. F. Minchin, "Cellular uptake of self-assembled cationic peptide-DNA complexes: multifunctional role of the enhancer chloroquine," Journal of Controlled Release, vol. 135, no. 2, pp. 159-165, 2009.

[136] J. S. Suk, J. Suh, K. Choy, S. K. Lai, J. Fu, and J. Hanes, "Gene delivery to differentiated neurotypic cells with RGD and HIV Tat peptide functionalized polymeric nanoparticles," Biomaterials, vol. 27, no. 29, pp. 5143-5150, 2006.

[137] S. R. Sirsi, R. C. Schray, X. Guan et al., "Functionalized PEGPEI copolymers complexed to exon-skipping oligonucleotides improve dystrophin expression in mdx mice," Human Gene Therapy, vol. 19, no. 8, pp. 795-806, 2008.

[138] E. Kleemann, M. Neu, N. Jekel et al., "Nano-carriers for DNA delivery to the lung based upon a TAT-derived peptide covalently coupled to PEG-PEI," Journal of Controlled Release, vol. 109, no. 1-3, pp. 299-316, 2005.

[139] J.-P. Behr, B. Demeneix, J.-P. Loeffler, and J. Perez-Mutul, "Efficient gene transfer into mammalian primary endocrine cells with lipopolyamine-coated DNA," Proceedings of the National Academy of Sciences of the United States of America, vol. 86, no. 18, pp. 6982-6986, 1989.

[140] W. T. Godbey, K. K. Wu, and A. G. Mikos, "Poly(ethylenimine)mediated gene delivery affects endothelial cell function and viability," Biomaterials, vol. 22, no. 5, pp. 471-480, 2001.

[141] W. T. Godbey, K. K. Wu, and A. G. Mikos, "Size matters: molecular weight affects the efficiency of poly(ethylenimine) as a gene delivery vehicle," Journal of Biomedical Materials Research, vol. 45, no. 3, pp. 268-275, 1999.

[142] W. T. Godbey, K. K. Wu, and A. G. Mikos, "Tracking the intracellular path of poly(ethylenimine)/DNA complexes for gene delivery," Proceedings of National Academy of Sciences of the United States of America, vol. 96, no. 9, pp. 5177-5181, 1999. 

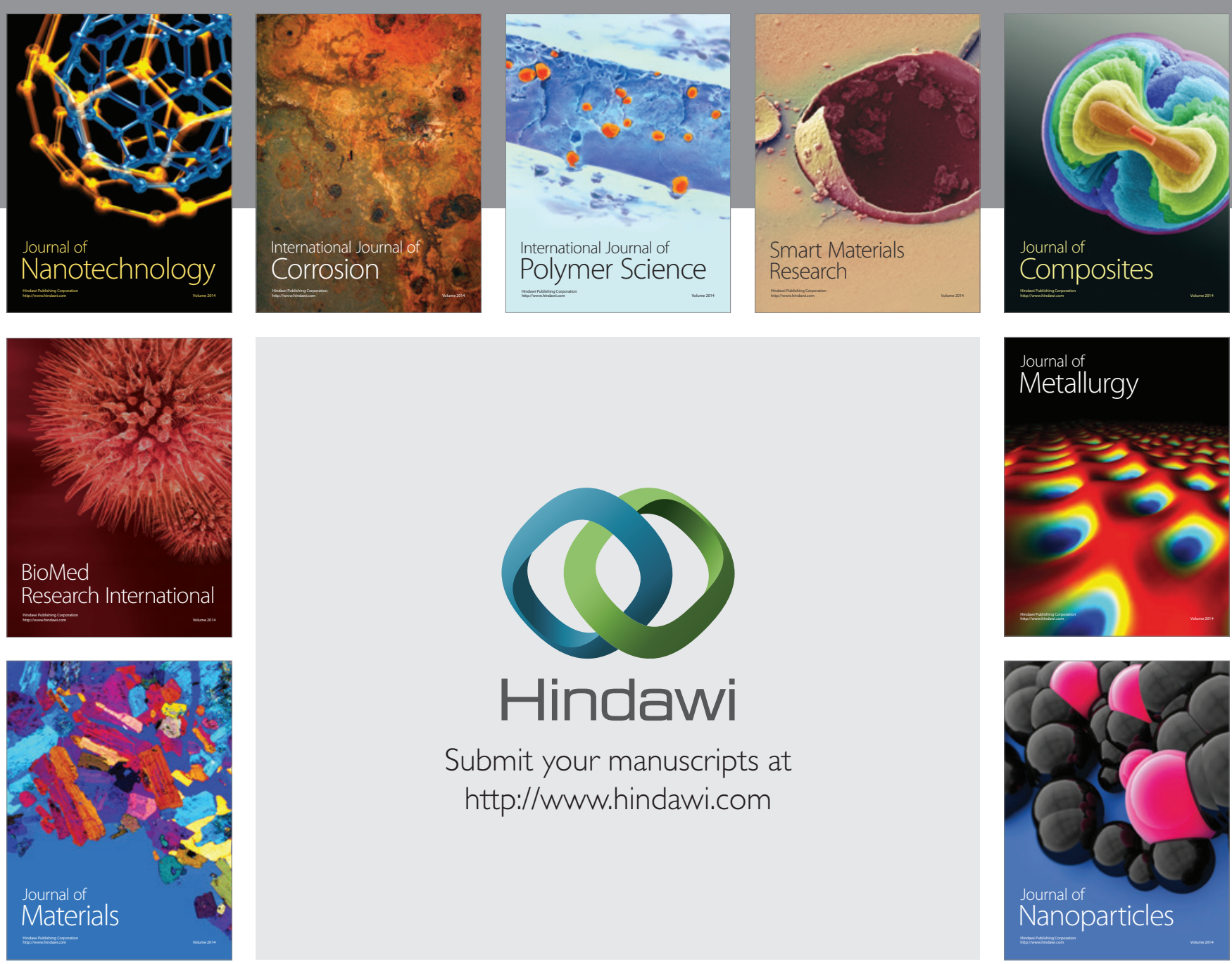

Submit your manuscripts at http://www.hindawi.com
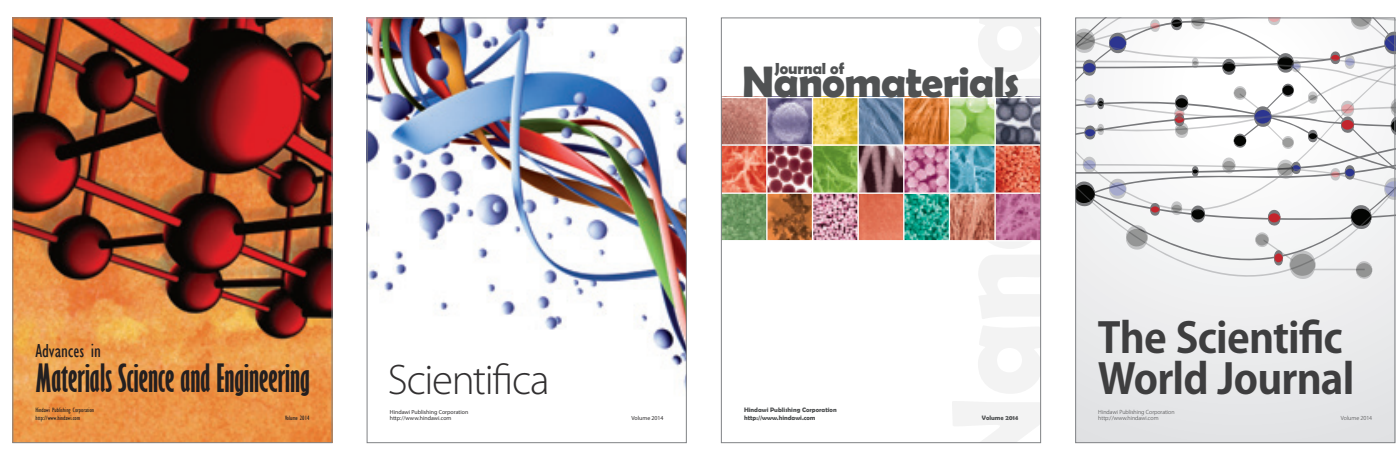

\section{The Scientific World Journal}
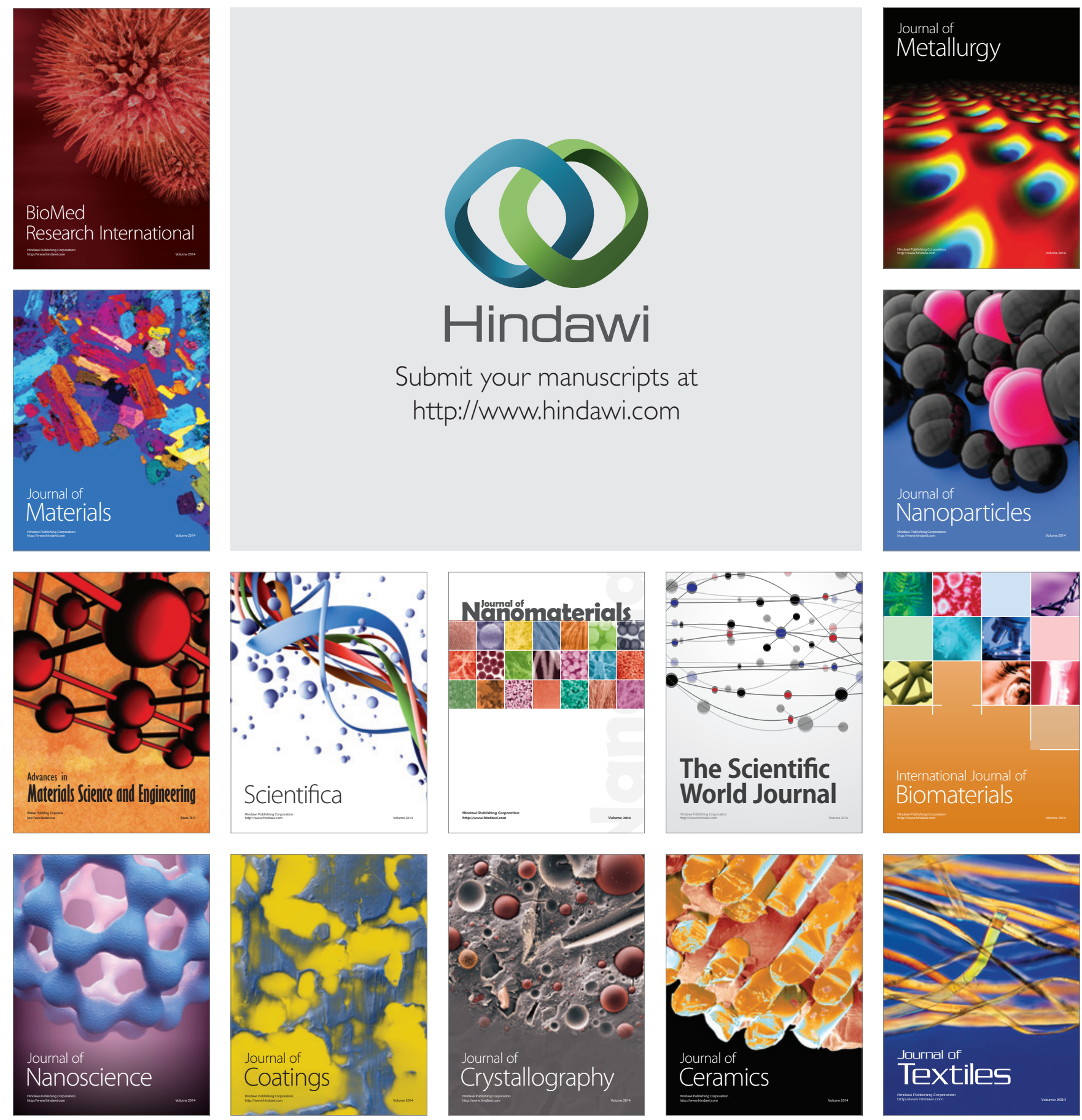